\title{
PE followed me home from school today: Effects of the Activity Challenge on youth summer physical activity
}

Kacey DiGiacinto

West Virginia University

Follow this and additional works at: https://researchrepository.wvu.edu/etd

\section{Recommended Citation}

DiGiacinto, Kacey, "PE followed me home from school today: Effects of the Activity Challenge on youth summer physical activity" (2010). Graduate Theses, Dissertations, and Problem Reports. 3244.

https://researchrepository.wvu.edu/etd/3244

This Dissertation is protected by copyright and/or related rights. It has been brought to you by the The Research Repository @ WVU with permission from the rights-holder(s). You are free to use this Dissertation in any way that is permitted by the copyright and related rights legislation that applies to your use. For other uses you must obtain permission from the rights-holder(s) directly, unless additional rights are indicated by a Creative Commons license in the record and/ or on the work itself. This Dissertation has been accepted for inclusion in WVU Graduate Theses, Dissertations, and Problem Reports collection by an authorized administrator of The Research Repository @ WVU.

For more information, please contact researchrepository@mail.wvu.edu. 
PE Followed Me Home From School Today:

Effects of the Activity Challenge on Youth Summer Physical Activity

\section{Kacey DiGiacinto}

Dissertation submitted to the

College of Physical Activity and Sport Sciences

at West Virginia University

in partial fulfillment of the requirements

for the degree of

Doctor of Philosophy

in

Kinesiology

with an emphasis in

Physical Education Teacher Education

Sean M. Bulger, Ed.D., Chair

Reagan P. Curtis, Ph.D.

Andrew B. Hawkins, Ed.D.

Ruth E. Kershner, Ph.D.

Robert L. Wiegand, Ed.D.

Coaching and Teaching Studies Department

Morgantown, West Virginia

2010

Keywords: comprehensive school physical activity programs, physical activity, summer program, physical education 


\begin{abstract}
PE Followed Me Home From School Today:

Effects of the Activity Challenge on Youth Summer Physical Activity

Kacey DiGiacinto
\end{abstract}

The prevalence of overweight and obese youth in the nation is growing at an alarming pace (Centers for Disease Control and Prevention, 2008; West Virginia Department of Health and Human Resources, 2007). Currently, 3.8\% of elementary schools, $7.9 \%$ of middle schools, and $2.1 \%$ of high schools provide daily physical education (Jones, Axelrad, \& Wattigney, 2007). That means that a majority of America's youth are not provided with the opportunity to accumulate the recommended daily amounts of physical activity. With formal physical education in mind schools should be focusing on increasing youth out-of-school physical activity. Teacher assigned, out-of-school, physical activity, self-management programs serve to provide the nation's youth with the best opportunity for increasing physical activity, without taking away from the existing in-school curriculum. The Activity Challenge (AC) is a physical activity program, modeled after the Summer Shape-Up Challenge, designed to increase youth physical activity during the summer and after school (National Association for Sport and Physical Education, 2005). To evaluate the effectiveness of the AC the researcher used a single-case combined $\mathrm{ABABC}$ reversal design and an $\mathrm{ABC}$ delayed multiple baseline design. The dependent variable was daily step count as measured by the New Lifestyles 800 brand of the Yamax Digiwalker pedometer. Steps counts indicated that the AC was not effective at increasing or maintaining participant out-of-school physical activity. 


\section{DEDICATION}

This dissertation is dedicated to my parents, Paul and Donna DiGiacinto, who worked hard to give me everything I ever needed and taught me to work hard to get everything I ever wanted.

This research is also dedicated to my best friend, Kimberly Ann Montesano (December 22, 1980- January 3, 2005), who brought me to the game of rugby and who has had the single biggest impact on my life, next to my parents. 


\section{ACKNOWLEDGEMENTS}

I would like to acknowledge some very important people and organizations. Without their help I would not have been able to complete my doctoral degree. Without West Virginia on the Move's Schools on the Move grant funding this research might not have taken place. Through their funding and support I was able to conduct not only this research study but also provide another program to the students at a local elementary school. The Schools on the Move grant initiative is integral to helping schools provide exciting, innovative, and effective opportunities for physical activity.

Dr. Sean Bulger has been one of the driving forces behind my efforts and accomplishments. Our work styles couldn't be more in sync and I am thankful for all his feedback and guidance. I can honestly say I work so hard because I don't want to embarrass him.

Dr. Reagan Curtis has the patience of a saint. He was always ready and willing to talk me through my SPSS woes. He is truly a statistics Guru.

Dr. Andrew Hawkins has provided countless hours of guidance for how to handle those touchy situations. I hope his expertise in single-case design continues to rub off for future research. The Hawkins hug is a thing to be studied: no triumph was every really a triumph without one and no failure ever seemed manageable without one.

Dr. Ruth Kershner is an incredible asset to have in one's corner. Without her guidance I never would have been able to earn my M.S. in School Health Education. Her frank and wild attitude is a refreshing whirl-wind, once you get used to that style. Her love for teaching really does rub off on every person with whom she comes in contact. 
Dr. Robert Wiegand has provided invaluable guidance in my teaching and my research. His knowledge of inferential statistics knows no bounds. He is truly a joy to work with and he was always able to put a smile on my face by calling me, "Kiddo."

Dr. Lynn Housner is also a very important part of this research. He made it possible for West Virginia University to donate the Natatorium pool for the mid-program family night. While he was not on the committee, he was always ready to discuss the design of this program and the implications for implementation. I truly appreciate all the professional development opportunities he offered to me during my time as a doctoral student.

I would also like to thank Dr. Yong Gao from Boise State University for providing me with feedback related to this research at the 2010 AAHPERD Research Consortium Works in Progress poster session. Her perspective was welcomed and I did use her suggestions to write my dissertation.

I want to thank Drue Stapleton for helping with this research study and always being ready to talk about ways to improve ourselves and our students. I also want to thanks Wes Meeteer for helping with the program meetings for this research study and for being a great convention companion and dancer. I want to thank Camille Ramsey for helping collect data for this study and for all her support, advice, and her sunny outlook on life. Camille's ability to see the positive in every situation is truly a gift. I also want to thank Dr. Brandonn Harris. Without his help I might not have survived my first year in my doctoral program. It was Brandonn who really showed me the ropes of doctoral education and graduate assistantship. Lastly, I want to thank Josh Craze. He has been very supportive of my work and way more understanding of my 
work style and my dedication to perfection than anyone should have been. He was always willing to do what he could to help be a better student, instructor, and researcher. 


\section{TABLE OF CONTENTS}

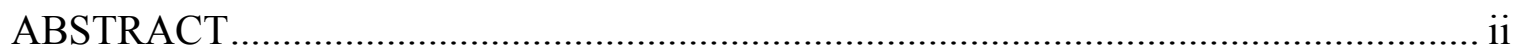

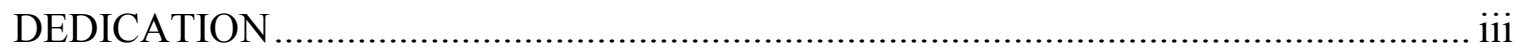

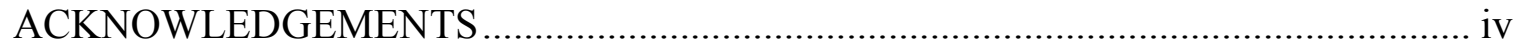

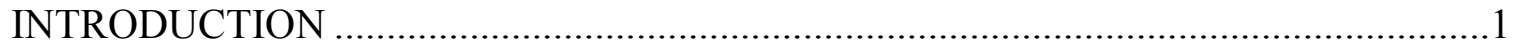

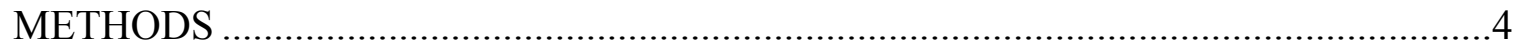

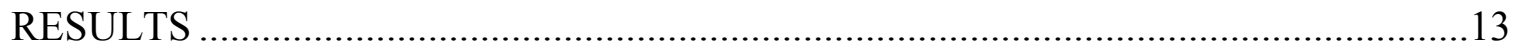

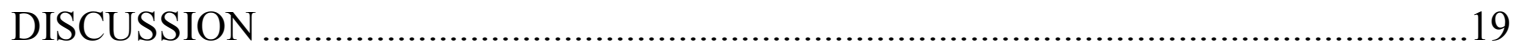

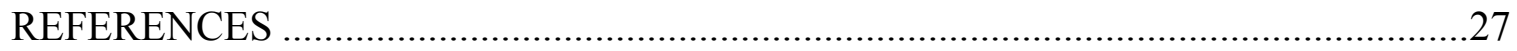

APPENDICES

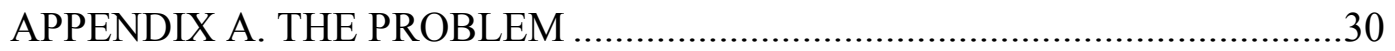

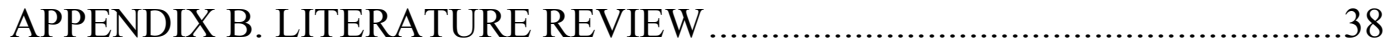

APPENDIX C. ADDITIONAL MATERIALS ............................................6

APPENDIX D. WVOM SCHOOLS ON THE MOVE GRANT ........................77

APPENDIX E. ADDITIONAL REFERENCES ............................................. 79 
PE Followed Me Home from School Today 1

\section{Introduction}

The occurrence of overweight and obesity is on the rise in every age-group of the population (Centers for Disease Control and Prevention (CDC), 2008; West Virginia Department of Health and Human Resources, 2007). Health risk factors associated with overweight and obesity are: increased low-density lipoprotein (LDL) cholesterol, increased triglyceride levels, decreased high-density lipoprotein (HDL) cholesterol, and increased risk of: stroke, heart disease (e.g., hypercholesterolemia and dyslipidemia, hypertension), hyperinsulinism, insulin resistance, impaired glucose tolerance, type 2 diabetes mellitus, menstrual irregularity, osteoporosis, some forms of cancer, and mental health problems (e.g., depression, low self-esteem) (American Academy of Pediatrics, 2003; American Heart Association, 2005; Freedman, Dietz, Srinivasan, \& Brenson, 1999; Gidding, Bao, Srinivasan, \& Berenson, 1995; U.S. Department of Health and Human Services (USDHHS), 1996, 2000b). One way to decrease the incidence of the health problems associated with overweight and obesity is to participate in regular, moderate amounts of physical activity (PA). The President's Active Lifestyle Program recommends boys and girls between the ages of 6-17 should accumulate 13,000 and 11,000 steps per day (SPD), respectively (The President's Challenge, n.d.). The health benefits associated with leading a physically active lifestyle are: building and maintaining healthy bones, muscles and joints, increasing cardiorespiratory endurance, controlling weight and reducing body fat, building lean muscle, preventing or delaying the development of high blood pressure and helping reduce blood pressure in some adolescents with hypertension, and reducing feelings of depression and anxiety (CDC, 1997; Fulton, Meenakshi, Galusk, Rattay, \& Caspersen, 2004; USDHHS, 1996, 2000a).

Increasing PA during youth and decreasing the amount of time spent sedentary has been linked to better health in adulthood. For example, Hancox, Milne, and Poulton (2004) concluded 
that overweight, poor fitness, and elevated cholesterol in adulthood have been linked to increased time spent sedentary (specifically television watching) during childhood. Many governments and professional organizations now recognize the link between youth PA and adult health benefits. The United States government focused the Healthy People 2020 Report on dedicating more attention to youth health related to overweight and obesity and increasing PA (USDHHS, 2009). In conjunction with the government recommendations the National Association for Sport and Physical Education (NASPE) (2004) has prescribed that youth between the ages of 5-12 should accumulate a minimum of 60 minutes, and up to several hours, of age-appropriate PA on all, or most days of the week. This PA should include a mixture of moderate and vigorous PA focusing on cardiovascular strength, flexibility, and muscular strength and endurance that should be accumulated during several bouts (at least 10 minutes in duration) throughout the day (NASPE, 2004). The current physical activity recommendations from the USDHHS (2008) reinforce NASPE's recommendations that youth should accumulate 60 minutes of moderate-to-vigorous PA daily including at least three days a per week of vigorous-intensity aerobic activity, muscle strengthening activity, and bone-strengthening activity.

While NASPE recommends schools provide elementary age students with 150 minutes of instructional physical education per week and 225 minutes for middle and high school students, many schools are falling short of this goal (Ballard et al., 2005). Currently, 3.8\% of elementary schools, $7.9 \%$ of middle schools, and $2.1 \%$ of high schools provide daily physical education (Jones, Axelrad, \& Wattigney, 2007). That means that a majority of America's youth are not provided with the opportunity to accumulate the daily recommended amounts of PA during the school day. With formal physical education in mind, schools should be focusing on increasing youth out-of-school PA in such a way that it supports learning and practice of learned skills and 
concepts covered in class (Ballard et al., 2005). If schools are going to influence the PA behaviors of their students then a comprehensive approach to school PA must be adopted (CDC, 1997; Pate et al., 2006; USDHHS, 1996; WHO, 2001). Comprehensive school PA programs need to start with the school and involve the family and community to help students be active before, during, and after school (NASPE, 2003). Likewise, the newly authored National Physical Activity Plan recommends physical education needs to, "work toward influencing students to increase PA in discretionary time" (Siedentop, 2009, p. S178). Based on these recommendations, structured after school or summer assignments can serve to improve the health of the nation's youth.

Structured programs such as Sports, Play and Active Recreation for Kids, Coordinated Approach to Child Health, the President's Active Lifestyle Award, President's Challenge, Presidential Champions, and Physical Best are already being used in schools across the country in an attempt to increase the amount of time youth spend engaged in PA out-of-school. The Activity Challenge (AC) is an out-of-school PA program that was modeled after the Physical Best Summer Shape-Up Challenge. The goal of both programs is to increase youth PA during the summer and after school by providing suggested categories of activities and by requiring participants to keep track of their PA (NASPE, 2005). Neither version of the program has been evaluated for program effectiveness. Hadley, Hair, and Dreisbach (2010) found programs that required tracking PA progress were "fairly" effective for helping motivate participants to be more active. Recommendations made by Siedentop (2009) are to keep researching the effectiveness of physical education and PA programs that aim to influence students to increase PA during discretionary time. The link between physical inactivity and overweight and obesity is well-known. There is a definite need to motivate youth to participate in the 60 minutes or more 
of daily of recommended activity. While there are already PA programs created to promote the increase in out-of-school PA, many of them have not been evaluated for effectiveness. Programs with narrow goals are more likely to be effective than those with broad goals so the goal of increasing physical activity was set for the AC (Pekruhn, 2009). Therefore, the purpose of this study was to evaluate the AC program to determine if it positively impacts the amount of PA the participants engaged in out-of-school.

\section{Methods}

This was a single-case study using an $\mathrm{ABABC}$ reversal design combined with an $\mathrm{ABC}$ delayed multiple baseline. The program was implemented once during the summer of 2009 and a second time during the fall of 2009. The study was conducted to assess if the program increased the amount of out-of-school PA participants accumulated.

\section{Treatment}

The AC was set up to challenge students to participate in six different categories of PA over the course of the program. The goals set for the AC were long term program goals and not daily goals. The participants were asked to participate in the first activity category, Tune Out. They then picked two other categories of activity to participate in for the course of the program. The categories are presented in Table 1. Participants were required to track their own progress using a combination of paper and/or electronic activity logs each week. Program incentives were in place for both the fall and the summer programs. Upon completion of the program participants an Awards Day was held during school lunch to showcase their efforts in front of their peers. Participants received an AC certificate and a gift bag filled with active prizes (e.g., jump ropes, kickballs, etc.). 
Table 1. Activity Categories and Descriptions

\begin{tabular}{|c|c|}
\hline Activity Category & Description \\
\hline Tune Out & $\begin{array}{l}\text { To complete this challenge you need to decrease the amount of time you } \\
\text { spend in front of the TV, computer, or video game screen during non- } \\
\text { educational activities. Limit your time with the TV, computer, and video } \\
\text { games to } 2 \text { hours a day for the whole program. }\end{array}$ \\
\hline Parents Like to Play, Too & $\begin{array}{l}\text { To complete this challenge, you must participate with one or both parents } \\
\text { or guardians at least } 1 \text { day per week for } 6 \text { weeks. Your activity session } \\
\text { should be at least } 20 \text { minutes long. }\end{array}$ \\
\hline Wheels in Motion & $\begin{array}{l}\text { Using your bike, scooter, roller skates, in-line skates or skateboard, } \\
\text { challenge yourself to log } 20 \text { miles between the program start date and the } \\
\text { program end date. }\end{array}$ \\
\hline Try Something New & $\begin{array}{l}\text { The challenge is for you to participate in an activity you have not tried } \\
\text { before. Find a friend or family member to help teach you necessary skills } \\
\text { to complete this challenge. Participate at least } 5 \text { more times during this } \\
\text { program and log the dates and time spent. }\end{array}$ \\
\hline Vacation Run & $\begin{array}{l}\text { Select a relative or friend you'd like to visit who lives in a nearby town. } \\
\text { Determine the distance to their house. Draw a map to plot the course of } \\
\text { your trip. As you run or walk during the program, log and chart your } \\
\text { mileage until you've reached your destination. }\end{array}$ \\
\hline Keep the Log Rolling & $\begin{array}{l}\text { Keep a log of your favorite activities. Challenge yourself to three } \\
\text { activities a week at } 20 \text { minutes in duration. Record date and time spent. } \\
\text { Suggested activities: ballet, basketball, baseball or teeball, bowling, golf, } \\
\text { gymnastics, hiking, jogging, hula hoop, jump rope, karate, playing catch, } \\
\text { soccer, tennis, dance class, waterskiing, and wrestling. }\end{array}$ \\
\hline
\end{tabular}


Weekly phone calls were made by the researcher to the homes of the participants to check and make sure they were comfortable with the program. The researcher spoke with participants and their parents or guardians to provide encouragement and prompt participants to record their activity. The researcher would also check to make sure the pedometer was working correctly and that they had enough activity sheets. If no one was home a message of encouragement was left on the answering machine and a contact number was left in case the participants had questions.

During the summer program a mid-program Family Night was created as a way to help keep participants focused on the program. The Family Night took place at a local pool and started with data collection of activity logs, questionnaires, and parent proxy reports. It also served to help create a sense of community among the participants of the program. The Family Night served as a way to clearly distinguish changes in phases during the program. A wrap-up night was held for the summer program to collect the pedometers, activity logs, and qualitative questions, and administer the last of the participant questionnaires and parent proxy reports.

\section{Participants and Setting}

School setting. This program was implemented at a local elementary school in Morgantown, West Virginia. The researcher located a grant opportunity through West Virginia on the Move and contacted the principal at the elementary school to ask for permission to submit an application for the West Virginia on the Move Schools on the Move Grant. As part of the grant requirements two programs were created to help increase physical activity at the school. The $\mathrm{AC}$ was one of the programs designed to meet the requirements of the grant. The principal gave permission for the programs to be implemented and for the grant to be submitted, and even 
wrote a letter of support during the grant application process. The principal and physical education teacher were informed and consulted with through e-mail and face-to-face meetings on advertisement materials, group meetings (Kick-off Event, Awards Day, etc.), and implementation of the program. The school was awarded $\$ 5,000$ by the Schools on the Move grant program.

The researcher attended a PTA meeting in an attempt to inform parents about the Schools on the Move grant, the AC, and recruited participants. The physical education teacher employed the help of the art teacher to create a bulletin board to advertise the AC in the gymnasium. Initial support for the program was great, but support waned as the physical education teacher decided not to return to the school for the following school year. Local businesses were eager to donate incentives for the participants that completed the program.

For the summer program the researcher held a Kick-off event, a mid-program Family Night, a Final Meeting Night, and an Awards Day. A mid-program Family Night was held to keep participants excited about the program and help the researcher maintain regular access to participants for data collection of activity logs, questionnaires, and proxy reports. In total six of the ten participants attended the Kick-off event, two of the eight participants attended the midprogram Family Night, held at a local pool, two of the eight participants attended the Final Meeting, and three were deemed to have completed enough of the program to receive Awards during the Awards Day ceremony. For the fall program the $\mathrm{AC}$ was administered during the school day and the $5^{\text {th }}$ grade homeroom teachers at the school were kind enough to allow the researcher access to the participants whenever the researcher needed to collect data. 
PE Followed Me Home from School Today 8

Summer program participants. Participants in the summer program were $3^{\text {rd }}, 4^{\text {th }}$, and $5^{\text {th }}$ grade students, who chose to sign-up for this elective family-based intervention. Ten participants started this program, three males and seven females; four completed the program and two yielded usable data sets. Two males and one female participant formally dropped out of the study; one female attended the first meeting and then never participated in any other aspect of the program; two females attended the first meeting and completed the first week of data collection and never participated in any other aspect of the program. Two of participants who did not have completed data sets were females. Participants were required to have regular access to the internet to participate.

Fall program participants. Participants in the fall program were recruited from the $5^{\text {th }}$ grade at the same elementary school. Ten participants started the fall program, five males and five females, and four yielded usable data sets. Data could be analyzed for four of the participants because of missing data due to a lack of research adherence. One male participant dropped out of the study. Of participants who did not finish the program one was male and four were females. Participants were not required to have access to the internet for this program, as the online component of activity logging did not work well during the summer program.

\section{Measurement}

Pedometer. Pedometers are used to measure ambulatory activity which serves as an approximation of the amount of PA a participant accumulates throughout the day (Bassett \& Strath, 2002). The New Lifestyles 800 brand of the Yamax Digiwalker pedometer was used to collect step count information for the participants. The New Lifestyles 800 features a 7-day memory which was helpful for the participants and researcher to use when recording multiple 
PE Followed Me Home from School Today 9

days of activity at one time. The Yamax Digiwalker brand was selected because of the tested reliability provided as an approximation of PA (LeMasurier et al., 2005). In a study conducted by Cardon and De Bourdeauhuij (2007), the Yamax Digiwalker pedometer step counts were verified by participant activity diaries (recorded by participants' parents) and MTI Actigraph accelerometers. The study indicated that, significant relationship was observed between mean step counts and minutes of Moderate to Vigorous Physical Activity $(r=.73, p<.001)$ (Cardon \& De Bourdeauhuij, 2007). The same study was also able to generate a regression equation to predict step counts based on minutes of MVPA; from that equation $(y=6,134+129 x)$ it can be deduced that 60 minutes of MVPA is equal to 13, 874 steps (Cardon \& De Bourdeauhuij, 2007).

Activity logs. During the summer program, participants had the option to enter their PA online or on paper. Participants were issued paper logs to help them record their PA. Participants used the paper logs to record their daily PA during the program, in case they did not have access to a computer for a short period of time. Both the paper and web format of the activity logs required participants to enter: (a) their name, (b) category of activity they participated in, (c) specific activity they participated in, (d) how long or how far they did the activity, (e) how hard they worked (easy, moderate, hard, very hard), (f) the amount of steps logged for that day and (g) the amount of screen time for that day.

Fall participants were issued paper logs as their only means to enter data. This decision was made for two reasons: (1) due to the low number of participants from the summer program who used the website to log their activity it was decided to simplify the program so that only paper logs would be used, and (2) during the school year the researcher had almost daily access to the students so the logs could be collected more frequently than they had during the summer program, resulting in a better return rate for activity logs. 
Parent proxy report and PA recall questionnaire. A 7-day PA recall questionnaire and parent proxy report were used to assess participant PA levels. The parent proxy report was administered to a parent/guardian of each participant at three points during the program. This report was used to assess the parent/guardian's perceptions of their child's PA before, during, and after the program. The parent proxy report was adapted from the National Survey of Children's Health (CDC, 2003). The PA recall questionnaire was administered to the participants to assess their PA levels before, during, and after the program. All PA recall questionnaires were collected: at the end of week 1, the end of week 4, and at the end of week 9 for the ABABC reversal design group. These PA recall questionnaires were collected: at the end of week 1, the end of week 5, and at the end of week 9 for the ABC delayed design group. The student PA recall questionnaire questions were adapted from the FITNESSGRAM (Meredith \& Welk, 2007) and the SPAN $4^{\text {th }}$ grade questionnaire, which was completed by over 5,000 $3^{\text {rd }}$ grade students (Coordinated Approach to Child Health, 2004). The PA recall questionnaires were conducted verbally and a list of alternative terms were provided to increase readability.

Qualitative questions. At the end of both programs four qualitative questions were distributed to the parents and the participants of the AC. Those four questions were: (1) What did you like about the AC? (2) What part of the AC didn't you like? (3) What could we change to make the AC more fun for you to complete? (4) What kept you from fully participating in the AC? These questions were asked as an attempt to find ways to improve the program. They were also an indicator of what kept the participants from participating fully in the AC.

\section{Design and Procedure}

This research study employed a single case combined ABABC reversal and multiple baseline design. In the description of the design A constitutes a baseline phase, B constitutes an 
intervention phase, and C constitutes the follow-up phase. Both of the summer participants, whose data could be analyzed, participated in an ABABC reversal design. During the fall, two participants, whose data could be analyzed, participated in the delayed $\mathrm{ABC}$ design and two participants participated in the $\mathrm{ABABC}$ reversal design.

The $\mathrm{ABABC}$ reversal was chosen to detect the effects the intervention had on motivating the participants to engage in PA. Starting at baseline allowed researchers to collect data on participants' usual PA participation. The intervention was implemented and it was expected that PA would maintain or increase from the baseline PA levels. A revert back to the baseline phase occurred during mid-program to examine if students decreased their activity while not in the program or maintained levels of PA. After the second baseline phase the intervention was reintroduced. During the follow-up phase the intervention was removed because the program was complete. The follow-up phase consisted of PA data collected for one week after the intervention was terminated.

The delayed $\mathrm{ABC}$ design was chosen to control for usual changes in PA. The participants in the delayed $\mathrm{ABC}$ design were considered the control group for the $\mathrm{ABABC}$ reversal group. Data were collected on the ABC design group for the four weeks of the program without implementation of the intervention. These data were used to confirm the behavior exhibited in the $A B A B C$ reversal group. During the fifth week of the program the students in the ABC design participated in the intervention with the same rules and slightly modified goals (goals were reduced by half so they had equal opportunity to reach the goals of the activity categories) as the $\mathrm{ABABC}$ reversal group. It was expected that once the $\mathrm{ABC}$ design group started the intervention they would show similar results in participation as the $A B A B C$ reversal group. 
Days that were recorded by the participant or observed by the researcher as having between zero and five hundred steps were not included in the data analysis. These days represent an artifact of the data collection process and not the actual behavior of PA exhibited by the participant. For example, if a participant forgot to wear his/her pedometer for part of the day he or she would have a low number not because of a lack of physical activity, but rather because of a data collection problem. Likewise, if a pedometer was accidentally reset the daily step count would be low and would not accurately represent the amount of activity engaged in by the participant.

\section{Reliability}

Summer program reliability. In order to examine reliability, the researcher checked the 7day memory of the pedometer of each of the participants on at least 3 different occasions during the course of the program. These checks were executed in order to assess if the pedometer was used correctly and if the participants were logging their step counts accurately. These checks provided verification that the pedometer was being worn correctly and that the self-report instruments were reliable. The researcher checked the pedometer' 7-day memory to make sure the data recorded by participants accurately matched the data recorded by the pedometer. Reliability checks occurred on twenty-eight days of the sixty-three day program, $44.4 \%$ of the days. When participant activity logs were compared to participant pedometers participants accurately recorded their SPD $79.6 \%$ of the time. In cases where there was a discrepancy between the self-report activity log and the pedometer the pedometer data was reported for the data collection procedures. 
Fall program reliability. Reliability checks during the fall program occurred weekly and when students were present twice a week. This was done to ensure the accuracy and completeness of the data. The 7-day recall on the pedometers made it possible to examine the data from each day the pedometer was worn. Reliability checks took place for fifty-eight of the sixty-four day program, allowing for reliability testing for $90.6 \%$ of the days.

Results

Impact of AC on Amount of PA

Results are presented in Figure 1. Pseudonyms were created for each participant. Kim was a $4^{\text {th }}$ grade student who participated in the summer study in the ABABC reversal group. Kim was able to meet the recommended 11,000 SPD during $32 \%$ of the baseline and follow-up days and $20 \%$ of the intervention days. Kim averaged 3,256 SPD during the first baseline, 5,506 SPD during the first intervention, 9,718 SPD during the reversal, 7,451 SPD during the second intervention phase, and 8,685 SPD during the follow-up phase. Kim was more active during the first intervention than the initial baseline phase, but her SPD also went up during the reversal phase and then declined during the subsequent intervention phase the follow-up phase. Kim's daily step averages were well short of the recommended 11,000 SPD. She recorded a total of 354, 267 steps during the study. Most of Kim's PA was accumulated by playing with friends and participating in lifestyle physical activities (for example: household repairs, shopping at flea markets, groceries, and home improvement stores). For the twenty-nine days Kim recorded screen time, she never reported watching more than the two hour limit recommended by the "Tune Out" category. Kim spent a lot of her activity time with her father during lifestyle 
activities and her friends during spontaneous play. Social support was a key component for Kim to accumulate her PA.

Josh was a $4^{\text {th }}$ grade student who also participated in the ABABC reversal group. Josh was able to meet the recommended 13,000 SPD during $45 \%$ of the baseline and follow-up days and $48 \%$ of the intervention days. Josh averaged 14,503 SPD during the first baseline, 10,712 SPD during the first intervention, 8,570 SPD during the reversal, 12,795 SPD during the second intervention phase, and 6,868 SPD during the follow-up phase. He recorded a total of 440, 945 steps during the study. Josh's activity levels started high during the baseline phase, declined during the first intervention phase, declined again during the reversal, then his average SPD increased during the reinstatement of the intervention, and declined again during the follow-up phase. Josh's averages by phase show that he was meeting the recommended 13,000 steps during the first baseline and that he was close to meeting that recommendation during the second intervention phase. Josh's PA was accumulated by participating in camp activities and team sports such as basketball, baseball, and football. Josh's PA took the form of very structured activity opportunities. Josh only recorded screen time for seven days and he reported watching more than the two hour limit recommended by the "Tune Out" category once. Community based PA programs were a contributing factor for the amount of PA Josh accumulated.

Brock participated during the fall program as a $5^{\text {th }}$ grader in the ABABC reversal group. Brock was able to meet the recommended 13,000 SPD during 15\% of the baseline and follow-up days and $13 \%$ of the intervention days. Brock averaged 9,267 SPD during the first baseline, 8,034 SPD during the first intervention, 10,701 SPD during the reversal, 9,123 SPD during the second intervention phase, and 7,306 SPD during the follow-up phase. Brock's average SPD declined from baseline when the first intervention phase occurred, then his average SPD increase 
during the reversal, followed by a slight decrease during the reinstatement of the intervention, and finally declined again during the follow-up phase. By looking at the averages across phases, it is apparent that Brock did not meet the recommended 13,000 SPD. He recorded a total of 449,565 steps during the study. Brock recorded his screen time for twenty-six days of the study and he never recorded a day where he watch more than the two hour limit set by the "Tune Out" category. Brock’s PA consisted of Karate and aerobic fitness such as jogging and walking.

Brice also participated during the fall program as a $5^{\text {th }}$ grader in the $\mathrm{ABABC}$ reversal group. Brice was able to meet the recommended 13,000 SPD during 0\% of the baseline and follow-up days and $17 \%$ of the intervention days. Brice's average SPD could not be calculated during the initial baseline phase due to the fact that he had washed his pedometer and he did not ask for a new one. Brice averaged 8,794 SPD during the first intervention, 7,404 SPD during the reversal, 10,632 SPD during the second intervention phase, and 8,810 SPD during the follow-up phase. He reported 290,608 steps during the study. Brice's PA appeared to decline when the intervention was removed, increase during the reinstatement of the intervention, and then decline again during follow-up. While his PA appeared to respond to the design of the research Brice's average SPD did not meet the recommended 13,000 SPD. Brice participated in structured activities like basketball and football to accumulate his daily PA. Brice did not report his screen time during this study. Like Josh, Brice relied on structured community based teams to accumulate his PA.

Paul participated during the fall program as a $5^{\text {th }}$ grader in the $\mathrm{ABC}$ delayed baseline group. Paul was able to meet the recommended 13,000 SPD during $74 \%$ of the baseline and follow-up days and 55\% of the intervention days. Paul averaged 15,409 SPD during baseline, 12,319 during the intervention, and 14,789 during the follow-up phase. Paul's activity was not 
affected by the changes in the intervention phases, as his average SPD were lower during the intervention phase than the baseline and follow-up phases. Paul was able to average the recommended 13,000 SPD average during the baseline and follow-up phases and almost met that average during the intervention. He was the most active participant recording a total of 823,510 steps during the study. Paul accumulated his PA by walking, rollerblading, and playing the team sports of football, soccer, and basketball. Paul reported his screen time for fifty-four days of the study. He never reported more than one hour of screen time and on thirteen occasions he reported he spent no time in front of a screen. Paul participated with his family during much of his activity. He had a lot of parental and sibling involvement.

Donna was also a participant in the ABC delayed baseline group during the fall program. Donna was able to meet the recommended 11,000 SPD during 24\% of the baseline and follow-up days and 33\% of the intervention days. Donna averaged 8,912 SPD during the baseline phase and 9,224 SPD during the intervention. Data could not be included for the follow-up phase as this participant was on vacation that week and did not report her activity. Donna did not meet the recommended 11,000 SPD during either phase. She reported a total of 306,937 steps during the study. For fifty-two days of the study Donna reported screen time she reported an hour or less of screen time per day. Donna's PA came in the form of structured activities like gymnastics and karate. Having access to community opportunities made is possible for Donna to be active.

The amount of PA in which the participants participated during the summer and the fall programs did not positively respond with the implementation of the AC (see Figure 1). Based on visual inspection no changes were observed related to mean, level, trend, or latency. Across the intervention recall questionnaires and parent proxy reports showed that the participants were 
active in participating in aerobic activity at least 5 days a week, muscular fitness activities $2-3$ days a week, and flexibility activities 3 days a week (NASPE, 2004).
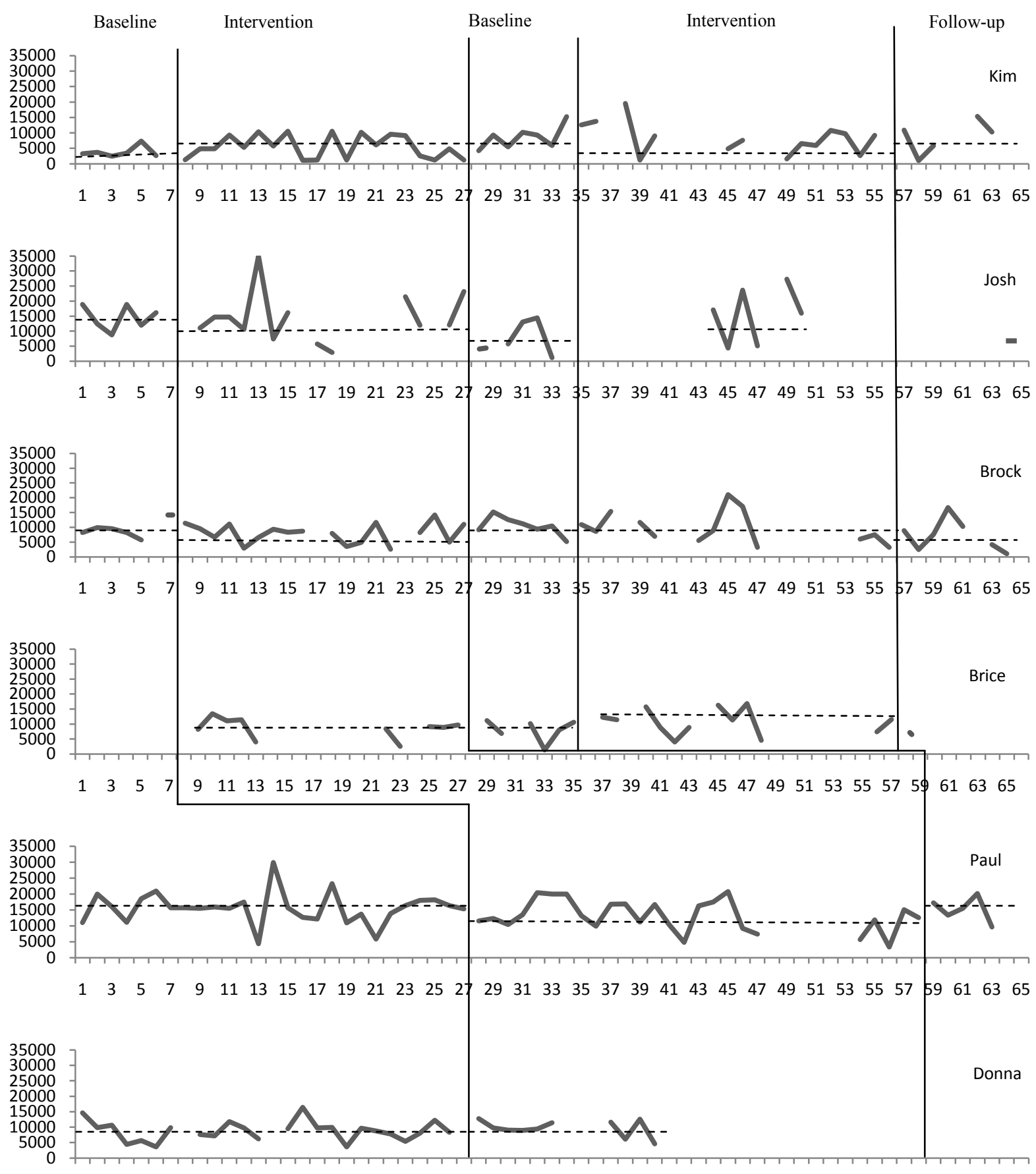

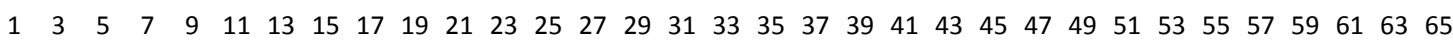

Program Days

Figure 1. Total steps per day during the 65 day program. Phase average lines were added for each participant to show the average number of steps per day that were accumulated during that phase. 
PE Followed Me Home from School Today 18

In Kim's case her answers on the participant questionnaire only differed from the answers on her father's parent proxy report on one item both times they participated in filling out the questionnaires and reports. During the baseline week, Kim's father reported she was one day less aerobically active than she reported and that she was not active at all in flexibility exercises while Kim reported that she had completed flexibility exercises at least once on the previous seven days. During the follow-up week, Kim reported engaging in flexibility exercises at least once on the previous seven days and again her father reported that she had not engaged in flexibility exercises.

Josh and his father participated fully in one round of participant questionnaires and parent proxy reports. During the first baseline week, Josh reported participating in no moderate activity while his father reported he participated in one day's worth of moderate activity. Josh's father also reported that Josh participated in one day less muscular strengthening activities than Josh reported. Josh's father also reported that Josh participated in two days more flexibility training than Josh reported. Josh's father also reported he spent one more hour watching television and playing video games than Josh reported.

During the fall program parent proxy reports matched the participant questionnaires $96.5 \%$ of the time. The only differences observed were on the parent proxy reports of Brice and Brock. Brice's mother had him participating in one less day of aerobic activity than Brice reported on the first questionnaire and on the third questionnaire Brice's mother recorded one less day of moderate intensity physical activity, one more day of muscular strengthening activity, and one hour more of video game playing than Brice reported. Brock's mother reported he was on the computer one hour more than he reported on the first questionnaire. When screen time was recorded on activity logs, it was only reported 1 day out of 158 days as exceeding the two 
hour limit set by the Tune Out category. That one day belonged to Josh from the summer program.

\section{Discussion}

These results indicate that in its current form the AC program did not increase out-ofschool PA. Problems existed regarding a lack of participant compliance in relation to both the treatment and data collection procedures. Participant attendance at the various orientation meetings, interaction through weekly telephone calls, and use of the program website for tracking progress was limited. All of the participants were not present during the Kick-off, midprogram Family Night, and Final Meeting. The summer participants shared that they thought the website was hard to understand and that sometimes the act of wearing the pedometer was a nuisance. Participants did reportedly enjoy getting weekly phone calls from the researcher that reminded them to wear their pedometers and log their activity although it was difficult to contact some families directly. Participants also indicated that they enjoyed the mid-program family night during the summer program. On that occasion, participants were able to socialize with each other at a local swimming pool.

In relation to data collection, the considerable number of partial data sets could be attributed to relying on self-report PA logs from the participants over the summer. During the fall, the researcher had direct access to the participants, which lead to more complete data sets. During the fall program, the researcher recorded the data right off the pedometers, but the participants often forgot to log their activity. It was common for participants in both the summer and fall programs to forget to wear their pedometers. As with previous studies (Bender, 
Brownson, Elliott, \& Haire-Joshu, 2005), parent proxy reports proved to be unreliable at recording child physical activity participation over the course of a seven day period.

The AC program was developed using a problem-based rather than theory-based approach (Ward, Saunders, \& Pate, 2007). A number of behavioral theories could be helpful in interpreting results and strengthening future iterations of the treatment. Behavioral economic theory or behavioral choice theory, for example, should be considered when planning a physical activity intervention. Behavioral choice theory suggests, "the choice of being active versus sedentary depends in part on the reinforcing value of the active and sedentary alternatives, as well as constraints on access to the alternatives" (Epstein, Roemmich, Saad, \& Handley, 2004, p.236). This means that youth frequently choose sedentary behaviors over active ones because sedentary behaviors are often easier to access than many physically active alternatives. PA and sedentary activity are concurrent contingencies with incompatible behaviors. There are essentially two ways a participant may spend his or her time, being active or sedentary (Malot \& Suarez, 2004). These two behaviors are incompatible, their reinforcers compete with each other, and the more rewarding behavior typically prevails. Many active behaviors involve having to change clothing, travel somewhere to participate in activity, and shower afterwards. Meanwhile, sedentary behaviors do not involve any of those components (Epstein \& Roemmich, 2001). Sedentary behaviors often provide enjoyment like a funny television show or a fun video game, which serve as immediate reinforcement, compared to being physically active, which has the delayed reinforcement of keeping an individual healthy or helping him lose weight over a long period of time. Physical activity does have built in immediate reinforcement, but much of that reinforcement requires being in adequate physical condition which requires effort and effort, itself, is often an aversive condition. The immediate reinforcement of sedentary activity usually 
wins over the delayed reinforcement of good, overall health. In this study the reinforcement of an incentive at the end of the program and better health were not strong enough motivators to completely combat the immediate reinforcement of sedentary activity.

Ecological theory also provides a means for explaining physical activity behavior and the related influencing factors. Ecological theory, at its core, asserts that multiple levels of influence and a person's environment must be interwoven to create a positive expectation of change (Ward, Saunders, \& Pate, 2007). Elements that should be considered when implementing out-ofschool, family-based PA programs should be: intrapersonal, interpersonal, organizational, community, and policy. In the case of this intervention those five elements require modification in order to achieve a higher rate of success.

The intrapersonal factors impacting this study were comfort level and involvement, website usage, and the schedule for reinforcement. Participants were comfortable participating in different forms of PA, but results indicated that participants needed more formal training on how to log their PA on paper and on the website. Keeping track of their PA was a common problem for participants in both interventions. Participants would have benefited from repetition when it came to recording PA. An area that could be used to improve the comfort of logging activity would be to have the physical education teacher instruct the students on how to complete the logs in class before they start the AC. Similar training could also be completed using the website during classroom time before the intervention started. Then students would already know how to $\log$ their activity for the program. Motivation also falls under intrapersonal influences towards physical activity and with that attention needs to be paid to the type of establishing operation used in the study. Michael (1993) asserts that an establishing operation is what makes a reinforcer valuable. While the summer program had a kick-off event, weekly phone calls from 
the researcher, a mid-program event, and an Awards Day, these reinforcements were not valuable enough to keep participants motivated to participate in PA and log their participation. Likewise, the end of program Awards Day and weekly phone calls from the researcher were not highly valued for the fall participants to stay vigilant about wearing their pedometers and recording their data. Something that would be perceived as holding more value would be weekly reinforcement incentives to participate in PA and log their activity could lead to better responses. To make the weekly reinforcement incentives more valuable recognition to the rest of the participants in the program is more motivating than just receiving a reward alone.

There were several interpersonal factors that could have influenced the participants in both positive and negative ways. Many of the participants reported being active with family members during the treatment. Having social support from friends and family members to be active helped some of the participants accumulate more activity than other participants. Likewise, if parents were not involved with the participants the participants were less likely to wear their pedometers or remember to log their activity. Research shows that interventions programs with a strong family component can work to help increase PA in participants (Hadley, Hair, \& Dreisbach, 2010). The researcher had limited access to the participants since she was only a community member providing PA programs and not a daily fixture in the school where the participants were located. There was little to no support from the physical education teacher during the summer program due to unforeseen factors that prompted her to change schools. The new physical education teacher, who started in the fall, was unable to dedicate sufficient time to the program because of challenges that occur with starting any new position. Perhaps if the physical education teacher at the school had been the one to offer the program the participants would have felt more responsibility to truly attempt the program with full effort. It is 
hypothesized that if the physical educator had been the one to publicize the program, recruit participants, train the participants in the use of the activity logs, and provide daily or weekly reinforcement the participants might have demonstrated greater adherence to the program.

There was organizational support from the school for the summer program, but support was more limited during the fall. The researcher received approval to offer the $\mathrm{AC}$ as a homework assignment where all the students in the $5^{\text {th }}$ grade would receive a grade based on logging their activity not on how much activity they completed. Unfortunately, one parent called and complained about the homework and administration decided not to require the program due to those parental concerns. Since students were not required to complete the assignment many chose not to participate in the program. The influence of school policy on children's participation in these types of school-based interventions needs to be examined more completely. O'Brein, Polacsek, MacDonald, Ellis, Berry, and Martin (2010) found that schools with policy support for PA were associated with decreased inactivity in student behaviors.

Community support of PA opportunities existed in this community. The community played an important role in the lives of the participants. Many participants engaged in community activities to accumulate PA. The activities included: day camps, sports teams (baseball, football, basketball, etc.), and activity classes (gymnastics, Karate, etc.). The community also contributed to the incentives the students received for participating in the AC. West Virginia University donated its pool for the summer mid-program family night. Gifts, gift certificates, season sports passes, and monies were donated by individuals and businesses in the community to reward participants who completed the program. 
PE Followed Me Home from School Today 24

As for public policy, the West Virginia on the Move's Schools on the Move grant opportunity made this program possible. A total of $\$ 5,000.00$ in funding was provided by the Schools on the Move grant. That money was used to purchase pedometers and incentives for this program. It is through funding opportunities like Schools on the Move, that schools have the finances to try new and exciting PA programs. If schools are to develop evidence-based approaches to promoting school PA this type of financial and technical support is needed.

Ecological approaches to PA promotion focus on intrapersonal, interpersonal, organizational, community, and policy to create an environment that will encompass many different behavioral influences and so should a Comprehensive School Physical Activity Program (CSPAP). A CSPAP should address those components before, during, and after school (NASPE, 2003). Ways to incorporate CSPAP are: create a CSPAP committee, conduct an assessment of the PA programming, create an action plan to find ways to improve physical education, before, during, and after school programming, staff \& employee wellness, and family and community involvement (NASPE, 2003). After creation of the action plan support needs to exist so the plan can be executed to improve the access to PA opportunity and the quality of PA.

\section{Implications for Practice}

While this study did not produce results indicating that the $\mathrm{AC}$ was effective at increasing or maintaining PA levels in elementary students outside-of-school it is the belief of the researcher that the program could be altered to produce a desirable impact. Specifically, future directions of this intervention should focus on (a) the participants' perceived self-efficacy to reach appropriate levels of PA by working on goal setting with more frequent reinforcement, (b) the participants' ability to properly log PA, (c) the social support participants have from family 
and friends to be active (as seen in this study family buy-in is a contributing factor to the amount of PA in which youth participate), (d) organizational changes to the program such as increased attention paid to it by the school, especially the physical education teacher before, during, and after the program, and (e) setting up opportunities for participants to be active together, at least weekly in their community. Behavioral economics supports integrating more regular reinforcement to help participants choose physical activity over sedentary activity. A more extensive analysis needs to be conducted to examine the start and stop dates of structured PA such as seasonal sports teams or specialty activities (for example: dance, Karate, etc.) to see if PA is totally dependent on community activities and not on discretionary activity like pick-up games and free play.

Summer program. While three sessions were designed to involve the families in the process of starting the program, maintaining the program, and awarding the participants for their hard work, family support was limited in some cases. In the future participants should be provided with more opportunities for the families to be involved with PA. A weekly field day could be offered for participants and their families to gather and participate in different activities in a non-competitive setting. This time could also be used to reinforce the importance of logging PA and perhaps collecting weekly PA logs in order to retain more complete data sets. These suggestions meet some of the recommendations described as "Promising Practices" by Hadley, Hair, and Dreisbach (2010).

Fall program. There was a difficulty garnering school support and creating an interdisciplinary opportunity for the program is advisable. Involving the general education teachers and physical education teachers at the school would create more support for the program and help reinforce the behavior of recording physical activity. General education teachers could 
allot class time to completing physical activity logs to help the participants remember to record their activity. General education teachers could also include information on physical activity time and step counts into math lessons and physical education teachers could work health and physical activity lessons in to their curriculums that include analysis of activity time and suggestions for activity. Having more organizational support like an interdisciplinary opportunity is supported by ecological theory (Ward, Saunders, \& Pate, 2007).

\section{Future Research}

The researcher already has plans for offering the AC, again, next summer. Changes will be made to the program to allow for more training of the participants and their parents at logging physical activity. A weekly PA component will be instated to allow participants and their families the opportunity to interact with each other in different activity settings like parks and pools. This weekly component will also allow the researcher to build better relationships with the participants to create more social support for the participants and their families. Weekly goal setting and recognition could be incorporated into this weekly field day to help keep participants excited about their physical activity. 
PE Followed Me Home from School Today 27

\section{References}

American Academy of Pediatrics. (2003). Prevention of pediatric overweight and obesity. Retrieved October 29, 2008, from http://www.pediatrics.org/cgi/content/full/112/2/424

American Heart Association. (2005). A Nation at Risk: Obesity in the United States. [Statistical Sourcebook]. Dallas, TX: Author.

Ballard, K., Caldwell, D., Dunn, C., Hardison, A, Newkirk, J., Sanderson, M., Thaxoton, V.S., \& Thomas, C. (2005). CD’s Recommended Standards For Physical Activity In School. North Carolina DHHS, NC Division of Public Health, Raleigh, NC: 2005.

Bassett, D.R. Jr., \& Strath, S.J. (2002). Use of Pedometers to Assess Physical Activity. In G.J. Welk (Eds.), Physical activity assessments for Health-Related Research (pp. 163-177). Champaign, IL: Human Kinetics.

Bender, J.M., Brownson, R.C., Elliott, M.B., \& Haire-Joshu, D.L. (2005). Children's physical activity: Using accelerometers to validate a parent proxy record. Medicine \& Science in Sports \& Exercise, 37, 1409-1413.

Cardon, G., \& De Bourdeaudhuij, I. (2007). Comparison of pedometer and accelerometer measures of physical activity in preschool children. Pediatric Exercise Science, 19, 205 214.

Centers for Disease Control and Prevention. (1997). Guidelines for school and community programs to promote lifelong physical activity among young people. $M M W R, 46$ (No. RR-6), 1-35.

Centers for Disease Control and Prevention. (2003). National Survey of Children's Health, 2003: State and Local Area Integrated Telephone Survey. Retrieved April 20, 2009, from http://www.cdc.gov/nchs/about/major/slaits/nsch.htm

Centers for Disease Control and Prevention. (2008). Comparison Between West Virginia Students and U.S. Students 2007 Youth Risk Behavior Survey. Retrieved November 8, 2008, from http://www.cdc.gov/HealthyYouth/yrbs/pdf/states/yrbs07_west_virginia_us_comparison. pdf

Coordinated Approach to Child Health. (2004). School Physical activity and Nutrition (SPAN) Questionnaire. Retrieved April 2, 2009, from http://www.sph.uth.tmc.edu/catch/catch_em/MeasureToolsDesc_01.htm

Epsteain, L.H. \& Roemmich, J.N. (2001). Reducing sedentary behavior: Role in modifying physical activity. Exercise and Sport Sciences Reviews, 29, 103-108.

Epstein, L.H., Roemmich, J.N., Saad, F.G., Handley, E.A. (2004) The value of sedentary alternatives influences child physical activity choice. International Journal of Behavioral Medicine, 11,236-242. 
Freedman D.S., Dietz, W.H., Srinivasan, S.R., \& Berenson, G.S. (1999). The relation of overweight to cardiovascular risk factors among children and adolescents: the Bogalusa heart study. Pediatrics, 103, 1175-1182.

Fulton, J.E., Meenakshi, G., Galusk, D.A., Rattay, K.T., \& Caspersen, C.J., (2004). Public health and clinical recommendations for physical activity and physical fitness: Special focus on overweight youth. Sports Medicine, 34, 581-599.

Gidding, S.S, Bao, W., Srinivasan, S.R., \& Berenson, G.W. (1995). Effects of secular trends in obesity on coronary risk factors in children: the Bogalusa heart study. Journal of Pediatrics, 127, 868-874.

Hadley, A.M., Hair, E.C., \& Dreisbacch, N. (2010). What works for the prevention and treatment of obesity among children: Lessons from experimental evaluations of programs and interventions. Washington, DC: Child Trends Fact Sheet.

Hancox, R., Milne, B., \& Poulton, R. (2004). Association between child and adolescent television viewing and adult health: A longitudinal birth cohort study. The Lancet, 364, 257-262.

Jones, S.E., Axelrad, R., \& Wattigney, W.A. (2007). Healthy and safe school environment, part II, physical school environment: Results from the school health policies and programs study 2006. Journal of School Health, 77, 544-556.

Le Masurier, G.C., Beighle, A., Corbin, C.B., Darst, P.W., Morgan, C., Pangrazi, R.P., et.al. (2005). Pedometer-determined physical activity levels or youth. Journal of Physical Activity and Health, 2, 159-168.

O’Brein, L.M., Polacsek, M., MacDonald, P.B., Ellis, J., Berry, S., Martin, M. (2010) Impact of a school health coordinator intervention on health-related school policies and student behavior. Journal of School Health, 80, 176-186.

Malot, R.W. \& Suarez, E.A.S. Principles of Behavior ( $5^{\text {th }}$ ed.). Upper Saddle River, NJ: Pearson Prentice Hall, 2004.

Meredith, MD \& GJ Welk. FITNESSGRAM / ACTIVITYGRAM Test Administration Manual (4th ed.) . Champaign, IL: Human Kinetics, 2007.

Michael, J. (1993). Establishing operation. The Behavior Analyst, 16, 191-206.

National Association for Sport and Physical Education. (2003). Comprehensive School Physical Activity Program [Position statement]. Reston, VA: Author.

National Association for Sport and Physical Education. (2004) Physical activity for children: A Statement of guidelines for children ages 5-12 ( ${ }^{\text {nd }}$ ed.). Reston, VA: National Association for Sport and Physical Education Publications

National Association for Sport and Physical Education. (2005). Physical education for lifelong fitness: Physical Best teacher's guide ( $2^{\text {nd }}$ ed.). Champaign, IL: Human Kinetics 
PE Followed Me Home from School Today 29

Pate, R.L., Davis, M.G., Robinson, T.N., Stone, E.J., McKenzie, T.L., \& Young, J.C. (2006). Promoting physical activity in children and youth: A leadership role for schools. Circulation: Journal of the American Heart Association, 114, 1214-1224.

Pekruhn, C. (2009). Preventing childhood obesity: A school health policy guide. Arlington, VA: National Association of State Boards of Education: Center for Safe and Healthy Schools.

The President's Challenge. The President's Active Lifestyle Program. Retrieved March 1, 2010, from http://www.presidentschallenge.org/the_challenge/active_lifestyle_rules.aspx

Siedentop, D.L. (2009). National Plan for Physical Activity: Education Sector. Journal of Physical Activity and Health, 6(Supp12), S168-S180.

U.S. Department of Health and Human Services. (1996). Physical activity and health: A report of the Surgeon General. Atlanta: Centers for Disease Control and Prevention.

U.S. Department of Health and Human Services. (2000a). Healthy people 2010: Understanding and improving health ( $2^{\text {nd }}$ ed.). Washington, DC: United States Government Printing Office.

U.S. Department of Health and Human Services. (2000b). Promoting better health for young people through physical activity and sports. Atlanta, GA: United States Department of Health and Human Services and Department of Education.

U.S. Department of Health and Human Services. (2008). 2008 Physical activity guidelines for Americans. Washington, DC: United States Government Printing Office.

U.S. Department of Health and Human Services. (2009). Proposed healthy people 2020 Objectives: Draft Objectives. Washington, DC: United States Government Printing Office.

Ward, D.S., Saunders, R.P., \& Pate, R.R. (2007). Physical activity interventions in children. Champaign, IL: Human Kinetics.

West Virginia Department of Health and Human Resources Bureau for Public Health. (2007). 2004-2005 West Virginia Behavioral Risk Factor Survey Report. Retrieved November 8, 2008 from http://www.wvdhhr.org/bph/oehp/hsc/pubs/BRFSS2004and2005/default.htm

World Health Organization. (2001). Obesity: Preventing and managing the global epidemic. Report of a WHO Consultation on Obesity, 3-5 June 1997, Geneva. Geneva, Switzerland: World Health Organization. WHO/NUT/NCD 98.1 


\section{APPENDIX A \\ PROBLEM STATEMENT}

\section{Statement of the Problem}

The purpose of this study was to evaluate the Activity Challenge (AC) to see if the program is effective at increasing out-of-school Physical Activity (PA). Currently the program, in its original form, has not been evaluated to see if it motivates participants to increase the amount of out-of-school PA in which they participate.

Scope of the Study

This study examined the program effectiveness of the AC at increasing the PA of $3^{\text {rd }}, 4^{\text {th }}$, and $5^{\text {th }}$ grade students. The AC is a modified version of the Summer Shape-Up Challenge that appears in the Physical Education for Lifelong Fitness: Physical Best Teacher's Guide second edition (National Association for Sport and Physical Education, 2005c). The AC was designed as a summer long program to motivate participants to participate in PA during the summer to supplement the lack of structured PA the participants would normally engage in during school physical education class. It was implemented as both a summer program and an after school program during the fall. Participants were presented six categories of physical activities to participate in for the duration of the program (9-weeks). All participants participated in the Tune Out category. This category limits screen time to two hours a day in an attempt to reduce sedentary activity. In addition to the Tune Out category participants chose two of the remaining five categories to participate in for the duration of the program. The remaining categories are: Wheels in Motion, Vacation Run, Parents Like to Play Too, Try Something New, and Keep the Log Rolling. Wheels in Motion requires participants to accumulate 20 miles on some sort of manually powered wheeled apparatus (e.g., bicycle, scooter, in-line skates, skateboard, roller 
skates, etc.). To fulfill the Vacation Run activity participants must identify a friend or relative in a nearby town and walk or run the distance to that person's house over the course of the summer. Parents Like to Play Too encourages participants to engage in some sort of PA with their parents/guardians for twenty minutes in duration once a week every week of the program. To complete Try Something New participants must select an activity they have never tried before and participate in that activity for twenty minutes in duration at least six times over the summer. In the Keep the Log Rolling activity participants must participate in three of their favorite activities as week for at least 20 minutes in durations for each activity. The participants that completed three of the six categories by the end of the program received: a program completion certificate, an AC t-shirt, activity pack, and recognition at their school during the Award's Day.

For the summer, ten participants were recruited from $3^{\text {rd }}, 4^{\text {th }}$, and $5^{\text {th }}$ grade students at at a local elementary school in Morgantown, West Virginia to participate in a single-case combined $\mathrm{ABABC}$ reversal design and an $\mathrm{ABC}$ delayed multiple baseline design. During the fall, ten participants were recruited from the $5^{\text {th }}$ grade students at the same school. The single case design was chosen to observe changes in the frequency of the daily PA in which the participants engage. The ABABC reversal design was selected to detect changes, if changes existed, in daily step count and reported PA between baseline, intervention, and follow-up phases on its own. A multiple baseline design was added to strengthen the study by controlling for usual changes in PA with its extended baseline phase. Using the two designs together will allowed the researcher to determine if PA increases observed during the ABABC reversal designs' intervention phases were influenced by the program or usual PA occurrences (such as structured sports leagues that are mainly played in June or the start of football season). 
Five participants were assigned to each research design group. The participants in the ABABC reversal group completed: a one week baseline phase, three week intervention phase, a one week return to baseline, another three week intervention phase, and then a one week followup phase. The delayed ABC group completed: a four week baseline phase, a four week intervention phase, and a one week follow-up phase. Data collection for the study will consist of: pedometers, paper activity logs, the AC program website, and periodic 7-day PA recall questionnaires.

For the purpose of this study, the dependent variable was daily step count as recorded by a pedometer. Steps counts were used as an approximation of daily accumulated PA. Participants entered their: daily step counts, type of PA, duration of PA, intensity of PA, and amount of screen time for the day on a paper log during week 1. Once the program started, beginning of week 2, participants had the option to enter their activity on a paper log or a special website constructed for the program that require participants to enter: their step count, activity category they participated in, type of PA they participated in, how long or how far they did the activity, how hard they worked during the activity, and the amount of screen time for the day. The website allowed for continuous submission of data so the participants did not have to save paper logs all summer or try to remember days of PA at a time. Participants rarely used the website to keep track of their PA. Three 7-day recall questionnaires were administered to each participant and parent proxy reports were administered to one parent/guardian of each participant over the course of the program. These 7-day recall questionnaires and parent proxy reports were used to assess the participant's PA trends before, during, and after the program and to check those trends against the self-reported daily activity. Paper questionnaires were used and the researcher read 
the questions aloud so the participants could ask questions if they did not understand the questions.

Pedometer reliability checks were executed three times during the intervention for each of the two participants who completed the summer program. The reliability checks were conducted at the end of the first, fourth, and ninth weeks. During the reliability checks the researcher examined the 7-day memory of the pedometers and compared that with the actual activity reported by the participants. Reliability checks examined the data for $44.4 \%$ of the days during the summer program. During the fall program the researcher checked the pedometers of the students twice a week allowing for the researcher to reliably check the pedometers for $90.6 \%$ of the days.

\section{Basic Assumptions}

1. Increasing PA is important for combating the health related risks associated with overweight, and obesity (Centers for Disease Control and Prevention, 1997; Fulton, et al., 2004; \& U.S. Department of Health and Human Services, 1996 \& 2000a).

2. Pedometers are a valid and reliable way to approximate the amount of ambulatory PA an individual participates in during the course of one day (Cardon \& De Bourdeauhuij, 2007; LeMasurier, et al., 2005).

\section{Limitations of the Study}

1. The study relies on self-reported PA by the participants. While treatment verification checks are in place there are still chances for participant error. There is also a concern 
that participants might fabricate their actual behavior based on the desire to complete the program.

2. Problems with over reporting of daily steps could occur due to social desirability. In an attempt to compensate for social desirability the participants will not be given a set amount of steps to try to accumulate daily or throughout the course of the program, therefore, the participants will not know how many steps they should be taking on a daily basis.

3. There are some concerns with the accuracy of the pedometers measuring PA not related to ambulatory activity, such as: arm exercises, push-ups, stretching, or lifting (Bassett \& Strath, 2002). Also, pedometers don't measure the intensity the wearer participates at or the duration of the PA. This means that the data will not tell the researcher if the participant spent more time engaged in moderate or vigorous activity or how long they were active during any given bout of activity.

4. Pedometers have also been found to record steps while the participant is riding in the car (Bassette \& Strath, 2002). A way to compensate for this problem is to have the wearer take the pedometer off in the car and lay it flat or turn it upside down. In cases where this situation could affect the data the self-reported website data will be used to verify the daily steps.

\section{Definition of Terms}

$\underline{\mathrm{PA}}$ - as any bodily movement produced by skeletal muscles that results in energy expenditure (Caspersen, Powell, \& Christenson, 1985, p. 126). 


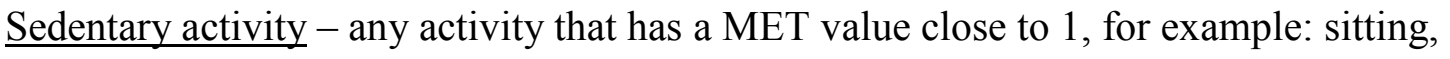
watching television, reading, etc. (Ainsworth et al., 1993).

$\underline{\text { Screen time }}-$ time spent sedentary in front of a television screen, computer screen, or video gram screen.

$\underline{\text { Single case design }}$ - research design used to conduct experimental investigations with one subject, or few subjects, and rigorously evaluate the effects of the intervention on the participants as individuals (Kazdin, 1982).

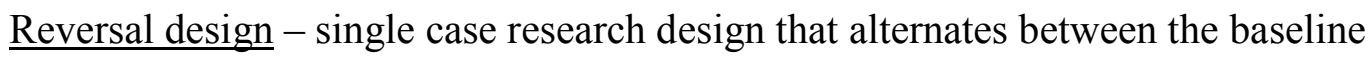
condition and the intervention condition more than once expecting that the desired behavior will improve during intervention and will revert back to baseline or near baseline when the intervention is withdrawn (Kazdin, 1982).

Multiple baseline design - single case research design where "the effects are demonstrated by introducing the intervention to different baselines at different points in time" (Kazdin, 1982, p. 126).

\section{Significance of the Study}

The past thirty years has seen an alarming increase in overweight and obese youth in the United States (Troiano, Flegal, Kuczmarksi, Campbell, \& Johnson, 1995). Health problems associated with overweight and obesity are: increased LDL cholesterol, increased triglyceride levels, decreased HDL cholesterol, and increased risk of: stroke, heart disease (e.g., hypercholesterolemia and dyslipedemia, hypertension), hyperinsulinism, insulin resistance, impaired glucose tolerance, type 2 diabetes mellitus, osteoporosis, some forms of cancer, and 
mental health problems (depression, low self-esteem) (American Academy of Pediatrics, 2003; American Heart Association, 2005; Freedman, et al., 1999; Gidding, et al., 1995; \& U.S. Department of Health and Human Services, 1996, 2000b). Meeting recommended amounts of daily PA are linked with many health benefits, such as: building and maintaining healthy bones, muscles and joints, increasing cardiorespiratory endurance, controlling weight and reducing body fat, building lean muscle, preventing or delaying the development of high blood pressure and helping reduce blood pressure in some adolescents with hypertension, and reducing feelings of depression and anxiety (Centers for Disease Control and Prevention, 1997; Fulton, et al., 2004; \& U.S. Department of Health and Human Services, 1996 \& 2000b).

It is also known that there is a significant correlation between youth PA participation and adult PA participation. Preparing students at an early age to be health conscious and physically active is the first building block towards healthy adulthood (Dennison, Straus, Mellits, \& Charney, 1988). Therefore, if American's want to combat the problems related to overweight and obesity they need to start young. One of the ways to combat overweight and obesity at a young age is by increasing time spent being physically active and decreasing the amount of time spent in more sedentary activity. It has been found that decreasing time spent pursuing sedentary pursuits like: watching television, playing on the computer (for non-school related purposes), and playing video games positively correlates with the amount of time spent engaged in physical (Robinson, 1999). Addressing PA in conjunction with school physical education is a great way for students to learn to be physically active outside of class. Ways PA can be addressed outside of class are by instituting afterschool or summer PA related assignments.

This study evaluated the effectiveness of the AC program to see if it motivated youth to increase PA levels. While the program was not successful at increasing PA it is the belief of the 
researcher that it could be reworked to successfully increase PA. When the program is reworked to increase physical activity schools could implement the program, easily without having to rework an entire curriculum, as an out-of-school physical education assignment for the purposes of combating overweight and obesity and teaching youth the importance of PA. 


\section{APPENDIX B REVIEW OF LITERATURE}

The review of the literature was included to provide a rationale for this study. The literature review will focus on: (1) health and PA trends, (2) health issues related to overweight and obesity, (3) PA recommendations for children and adolescents, (4) guidelines for school PA, and (5) strategies for improvement: self-managed, out-of-school PA assignments. There are four types of sources cited in this literature review; Type 1 are national, state, and local government documents providing guidelines for youth PA and statistics related to youth health and PA, Type 2 are nationally accredited health organizations (examples: American Heart Association and American Academy of Pediatrics) providing guidelines for youth PA and statistics related to youth health and PA, Type 3 are peer-reviewed research articles related to PA trends in physical education and the implementation of self-management programs for out-of-school PA assignment, and Type 4 are books published on physical education programs and selfmanagement programs for out-of-school PA assignments. EBSCO HOST, Google Scholar, and the Centers for Disease Control and Prevention's website were used to locate the resources for this literature review. Key terms used during the searches of each of those search engines were: youth PA, physical education, self-management, PA trends, television viewing and health, sedentary activity, youth inactivity statistics, overweight, obesity, obesity health consequences, overweight health consequences, obesity and overweight prevention. School PA and Nutrition survey, Child and Adolescent Trial for Cardiovascular Health, Coordinated Approach to Child Health, President's Active Lifestyle Award, Sports, Play and Active Recreation for Kids, Physical Best, Summer Shape-Up Challenge, pedometer, pedometer reliability, pedometer and bicycling reliability, parent proxy report, youth PA survey, and youth health trends. 
Health and PA Trends in the United States and West Virginia

A dramatic increase in physical inactivity and obesity has been observed in the general population over the last 30 years (United States Department of Health and Human Services, $1980,1996,2000 \mathrm{~b})$. Nationally $60 \%$ of Americans are not regularly active and $25 \%$ are not active at all meanwhile, "almost half of American youths 12-21 years of age are not vigorously active on a regular basis" (U.S. Department of Health and Human Services, 1996, p. 12). A lack of PA and increased time spent in sedentary pursuits has contributed to a higher prevalence of overweight and obesity. This trend is now observable at every stage in life. Youth PA trends have come into the spotlight in recent years due to the growing occurrences of childhood overweight and obesity; West Virginia ranks $3^{\text {rd }}$ in the nation for overweight adults and $6^{\text {th }}$ in the nation for overweight high school students (Centers for Disease Control and Prevention, 2008a; West Virginia University, 2008). The medical costs for obesity in 2003 in West Virginia were an estimated \$325 per person which caused the West Virginia Bureau for Public Health to call for a "statewide obesity prevention partnership" to address the obesity epidemic in the state (West Virginia University, 2008, p.1). In the United States in 2005, 24.5\% of adults were considered obese and 36.8\% were considered overweight (West Virginia Department of Health and Human Resources, 2007). In West Virginia during that same year, 30.6\% of adults were considered obese (according to BMI) and 34.8\% of West Virginia's adults were considered overweight (West Virginia Department of Health and Human Resources, 2007). Since these data were reported, the percentage of adults considered obese (BM30\%) in West Virginia has dropped slightly to $29.5 \%$ (Centers for Disease Control and Prevention, 2008c). According to the Centers for Disease Control and Prevention's Youth Risk Behavior Survey, nationally 13\% of students are obese, meanwhile $14.7 \%$ of West Virginia's students are obese; the prevalence of overweight 
is at the highest it has been, since data has been collected, and it is likely to be the highest in history, considering PA was more prevalent in all previous generations (Centers for Disease Control and Prevention, 2008b; Troiano, Flegal, Kuczmarksi, Campbell, \& Johnson, 1995). It is only deteriorate further when one considers "the probability of childhood obesity persisting into adulthood is estimated to increase from approximately $20 \%$ at age 4 to approximately $80 \%$ by adolescence” (Ferrera, 2005, p. 17).

Taking the previous statistics into account, in West Virginia in 2008, 42.8\% of middle school students reported being physically active for at least 60 minutes per day on five or more days last week (West Virginia Department of Education, 2008). What that means is that less than $50 \%$ of West Virginia's youth are meeting the recommendations for daily PA. Along with a decrease in PA outside of school PA in school is suffering also; "daily enrollment in physical education classes has declined among high school students from $42 \%$ in 1991 to $25 \%$ in 1995 " (U.S. Department of Health and Human Services, 1996, p. 10). What these numbers indicate is a drastic movement toward sedentary activity.

Just how much time are today's youth spending in sedentary pursuits. The answer is: too much time is spent watching television, playing video games, and playing on computers (for non-school purposes) to accumulate recommended amounts of PA. According to Rideout, Foehr, Roberts, and Brodie (1999), a national survey conducted by the Kaiser Family Foundation found that young people aged 2-7 spend, on average, 3.5 hours a day and young people aged 8-18 spend, on average 6.70 hours a day watching television, watching videotapes, playing video games, or using a computer. We know that these sedentary pursuits are major influences on when and if youth decide to participate in PA. Limiting the time children are allowed to spend watching television, playing on the computer, and playing video games has been linked to 
increases in PA (Robinson, 1999). Teachers and parents need to encourage students to play and be physically active while at the same time presenting conditions that will promote PA not sedentary activity.

\section{Health Issues Related to Overweight and Obesity}

\section{Health Issues Related to Physical Inactivity}

With increases in sedentary activity come increased risks of becoming overweight and obese and that leads to increased health risk factors. Consequences associated with overweight and obesity include: increased LDL cholesterol, increased triglyceride levels, decreased HDL cholesterol, and increased risk of: stroke, heart disease (e.g., hypercholesterolemia and dyslipedemia, hypertension), hyperinsulinism, insulin resistance, impaired glucose tolerance, type 2 diabetes mellitus, osteoporosis, some types of cancer, and mental health problems (depression, low self-esteem) (American Academy of Pediatrics, 2003; American Heart Association, 2005; Freedman, et al., 1999; Gidding, et al., 1999; U.S. Department of Health and Human Services, 1996, 2000b). Almost $\$ 100$ billion a year (approximately $8 \%$ of the national health care budget) is used to treat diseases associated with obesity (U.S. Department of Health and Human Services, 2000b). The only risk behavior that kills more people in the United States than physical inactivity is smoking; an estimated 300,000 deaths per year are attributed to the combination of physical inactivity and poor diet (McGinnis \& Foege, 1993). What can be done to stop the rise in these health risks?

\section{Health Benefits of Physical Activity}

There seems to be a consensus that an increase in time spent being physically active plus better nutrition and a decrease in sedentary activity will lead to healthier individuals (American 
College of Sports Medicine, 1988; Hughes \& Reilly, 2008; National Association for Sport and Physical Education, 2004a, 2004b; President's Council on Physical Fitness and Sport, 2003, 2007; Robinson, 1999; U.S. Department of Health and Human Services, 2000b). Physically active children are less likely to experience the health related risk factors associated with sedentary behavior (Hughes \& Reilly, 2008). Effects of an active lifestyle include: building and maintaining healthy bones, muscles and joints, increasing cardiorespiratory endurance, controlling weight and reducing body fat, building lean muscle, preventing or delaying the development of hypertension and helping reduce blood pressure in some adolescents with hypertension, and reducing feelings of depression and anxiety (Centers for Disease Control and Prevention, 1997; Fulton, et al., 2004; U.S. Department of Health and Human Services, 1996, 2000b). Research studies have even found an increase in PA leads to better conduct and higher academic performance (Zill, Nord, and Loomis, 1995; U.S. Department of Health and Human Services, 2000b). The health benefits of PA can be seen even with minimal amounts (30 minutes a day) of PA. This health information has been used by many government agencies to develop guidelines and plans for action towards motivating American's to participate in PA to achieve more optimal health.

\section{Physical Activity Recommendations}

\section{American Academy of Pediatrics}

In 1987, The American Academy of Pediatrics released a position statement on Physical Fitness and the Schools. At the time the A merican Academy of P ediatrics ex pressed concern related to the growing concerns as sociated with youth and physical fitness and PA. The position statement expressed concerns that youth PA would be threatened by four main problems:

1. Financial strains my lead public school systems to reduce physical education budgets. 
2. W idespread di senchantment $\mathrm{w}$ ith the $\mathrm{r}$ esults of $\mathrm{s}$ everal de cades of " progressive education e xperiments" has $\mathrm{r}$ esulted i n p ressures on s chool a dministrators to do a way w ith "frills" a nd to return to the "basics"; thi s might le ad to de-emphasis of ph ysical edu cation classes.

3. Children and adolescents are lured to watch television in their spare time.

4. Finally, most aerobic activities (e.g., running, swimming laps) are not perceived to be pleasurable, and it is extremely di fficult to motivate c hildren to begin a lif elong ha bit of maintaining a hi gh $\mathrm{d}$ egree o $\mathrm{f}$ ph ysical $\mathrm{f}$ itness if $\mathrm{t}$ his i nvolves $\mathrm{r}$ epeated e ndurance ph ysical activities. (p. 449)

The article called for a "curricular swing" from team sports oriented physical education (football, baseball, etc.) to lifetime PA promotion (cycling, swimming, tennis, etc.). Twenty-two years 1 ater it is obvious that the fears expressed in the Physical Fitness in the Schools article were valid. Physical education class time has be en reduced considerably at most s chools and students continue to participate in less PA than they have in previous generations. Today many schools still teach a team sport oriented curriculum and lifetime activities are not addressed in many school systems (American Academy of Pediatrics, 1987).

Centers for Disease Control and Prevention

The CDC's March 7, 1997 Morbidity and Mortality Weekly Report focused on PA in children and youth, how it is delivered, and how it is affected by personal and outside forces. This report was compiled, based on an in-depth review of research, theory, and current practice in physical education, exercise science, health education, and public health. The purpose was to summarize, for professionals who design and deliver PA to children and adolescents, recommendations for encouraging PA in children and adolescents in such a way as to promote 
the continuance of engagement in PA through adulthood in order to obtain the health benefits of PA for a lifetime. The 10 guidelines presented in the report focus on: policy, environment, physical education, health education, extracurricular activities, parental involvement, personnel training, health services, community programs, and evaluation. The report acknowledged: demographics, individual factors (confidence in one's ability, perceptions of PA or sport, and attitude toward physical education), interpersonal influences (friends, siblings, parents, and teachers), and environmental factors as determinants for participation in PA in youth. The report strongly recommended the hiring of certified physical education specialists to ensure that the little physical education students did experience in class was effective in providing them with an ample amount of PA time and information about PA that the students could employ at any stage in life. The report also advocated involvement with physical educators, parents, and policy makers as a way to ensure that physical education had a place in the school curriculum and that adequate space was allotted to schools and community areas so PA could take place in organized and spontaneous settings. It is necessary that PA never be used as a punishment and should never be withheld as a punishment. The main goal of the guidelines was to help students develop an appreciation for living an active lifestyle for a lifetime.

\section{U.S. Department of Health and Human Services}

In 2000, President Clinton instructed the Secretary of Health and Human Services and the Secretary of Education to put together a report that provide strategies to promote better youth health practices by utilizing PA and fitness. Approximately 90 days later he approved the U.S. Department of Health and Human Services release of Promoting Better Health for Young People Through Physical Activity and Sports. This report draws attention to what Americans need to do to increase PA in children at home, in school programs, during after-school care, in youth sports 
and recreation programs, in community structured environments, and media campaigns. The report indicated that while most schools are cutting physical education and PA time during the school day in order to allow for more class time to be allocated to math, science, and reading courses physical education has not been shown to negatively affect test scores. In fact, one study even found that physical education produced favorable results in test scores (Sallis, et al., 1999). The report also identified PA discouraging societal practices such as: community roadblocks for access to PA, schools that don't provide enough PA, and parental display of negative attitudes towards PA. Suggestions were provided for removing the roadblocks: designing well maintained well-lit sidewalks, bike lanes, and walking/biking trails, investing in parks and recreation areas in and around communities, creating community activity programs, providing free bus transportation for youth to and from pools, parks, recreation leagues, and other program activities, providing before and after school opportunities for PA by the schools, and promoting parental involvement in PA. The report suggests extracurricular PA programs can be effective at motivating youth to increase PA if the programs: 1) feature a diverse selection of competitive and non-competitive, structured and unstructured activities, 2) meet the needs and interests of all students, and 3) focus on enjoyment without pressuring participation or performance.

\section{National Association for Sport and Physical Education}

In 2002, National Association for Sport and Physical Education produced the Active Start guidelines for children birth to five years. The official statement is: "All children birth to age five should engage in daily PA that promotes health-related fitness and movement skills" (p.2). This statement breaks down to at least 60 minutes of daily, structured, age appropriate, PA for preschoolers and 30 minutes for toddlers. The five guidelines for each level of development from birth to age five have been created due to the presence of an increase in adult diseases in 
children caused by a sedentary lifestyle. PA during infancy is important to the development of brain function and help increase full developmental function of the brain-muscle connection. Between the ages of six months and three years children develop skills that will help with the development of hand-eye coordination and promote the development of strength, balance, flexibility, and cardiovascular endurance. The preschool ages see effects of PA in large muscle development, locomotor, non-locomotor, manipulative skills, balance, strength, spatial awareness, cognitive learning, and body management. Activities, equipment, space, and time that should be allotted to those activities are listed under the guidelines for each age group to help parents and caregivers understand what they should be doing for a child. For instance if children are not allotted enough space for their age group their development of gross motor skills, balance, and other areas of growth could be stunted due to inadequate room to move, run, skip, hop, and play. Children who do not play with balls and other objects that are easily handled, thrown, and caught can suffer hand-eye coordination problems. These guidelines even include a question and answer section to answer some of the more common questions parents have about appropriate ways to infuse their children's daily lives with more PA.

In 2004, the National Association for Sport and Physical Education produced a set of PA guidelines for children ages 5-12. These guidelines were designed so that parents and educators could easily integrate PA into the lives of the youth they come in contact with. The four guidelines focused on:

Guideline 1- Children should accumulate at least 60 minutes, and up to several hours, of age-appropriate PA on all, or most days of the week. This daily accumulation should include moderate and vigorous PA with the majority of the time being spent in activity that is intermittent in nature. 
PE Followed Me Home from School Today 47

Guideline 2- Children should participate in several bouts of PA lasting 15 minutes or more each day.

Guideline 3- Children should participate each day in a variety of age-appropriate physical activities designed to achieve optimal health, wellness, fitness, and performance benefits

Guideline 4- Extended periods (periods of two hours or more) of inactivity are discouraged for children, especially during the daytime hours. (NASPE, 2004b, p. 3-4)

The guidelines also present a balance of 4 levels of PA in the form of a pyramid in hopes of presenting a user friendly visual for students, parents, and teachers to learn the difference in activity levels and the combinations appropriate for children. The guidelines recommend that children (ages 5 to 9) should accumulate most of their daily PA engage in Level 1, Lifestyle Activities (walk to school, yard work, chores, play outside). Children (ages 5 to 9) should participate in some daily vigorous PA Level 2, Active Aerobics (running, jumping, biking) and Active Sports and Recreation, but it does not need to be continuous. Youth 10 to 12 should begin to make more choices at Level 2 for PA. For children, some weekly activity (3 days) should be focused on Level 3, Exercises for Flexibility and Muscle Fitness, "to overload the muscle in a way that promotes muscle fitness and flexibility development" (NASPE, 2004b, p. 15). Level 4 is Inactivity or Sedentary Living and it should be minimized as much as possible.

\section{American Heart Association}

This paper made many recommendations for increasing the amount of PA children and youth encountered on the way to and from school, before school, during school, and after school in order to help them reach the prescribed 60 minutes of daily PA (American Heart Association, 
1995). Due to the decrease in the amount of children who walk to and from school and due to recess being reduced or eliminated from the school day today's youth have not been getting the same amount of PA they were getting 20 years ago. This report found that few schools were meeting the weekly recommended 150 minutes for elementary schools and 225 minutes for middle and senior high schools for physical education. Citing the School Health Policies and Programs Study (SHPPS) the report indicated physical education class activity trends as consisting of $98.2 \%$ of schools teaching group/team activities, $97.4 \%$ teaching individual or partnered activities, $69.3 \%$ teaching dance activities, and $12.5 \%$ teaching aquatic activities (Pate, et al., 2006). The SHPSS data also showed that while most schools had interscholastic sports teams available there were only intramural activities present at $49 \%$ of the schools. Programs that were effective at increasing levels of moderate-to-vigorous PA in schools were: Child and Adolescent Trial for Cardiovascular Health (CATCH), Go for health, Lifestyle Education for Activity Program, Middle School Physical Activity and Nutrition (M-Span), Pathways, Sports, Play, and Active Recreation for Kids (SPARK), and Trial of Activity for Adolescent Girls (TAAG). Just by using the CATCH model and not increasing the frequency or duration of PA lessons moderate-to vigorous PA during PE increased by 15\% in intervention schools (p. 1217). Based on this data PA needs to be promoted on the way to and from school, during recess, in physical education classes, intermittently throughout the school day, and after school in order to get children and youth the adequate amount of PA.

\section{Physical Activity Guidelines Advisory Committee}

The PA Guidelines Advisory Committee studied health related issues associated with: all-cause mortality, cardiorespiratory health, metabolic health, energy, balance, musculoskeletal health, functional health, cancer, mental health, adverse events, youth, and understudied 
populations and issued this executive summary based on integrating current scientific information on the relation between PA and health in order to develop the Physical Activity Guidelines for Americans. This summary clearly defines what health improvements people could expect following differing levels of PA at different ages. The executive summary supports other government statements and guidelines which propose: daily PA will positively increase health by helping lower the chances of all-cause mortality, coronary heart disease, high blood pressure, stroke, type 2 diabetes, metabolic syndrome, colon cancer, breast cancer, and depression. Even individuals who are overweight or obese can benefit from being physically active; they can absolutely achieve health benefits similar to those who are of optimal body weight. The report even goes so far as to support that if a person participates in 1 hour per week of moderateintensity PA that amount will lower the risk of all cause mortality and the incidence of coronary heart disease. Literally any extra PA a person can do will benefit his health as long as it is on a level for which it is appropriate for him to participate. The report recommends children and youth to participate in 60 or more minutes of moderate to vigorous PA intermittent throughout the day focusing on, "resistance exercise to enhance muscular strength in the large muscle groups of the trunk and limbs, vigorous aerobic exercise to improve cardiorespiratory fitness and cardiovascular and metabolic disease risk factors, and weight-loading activities to promote bone health" (U.S. Department of Health and Human Services, 2008, A-5). When youth participate in 60 or more minutes of moderate to vigorous PA daily important health and fitness benefits can be expected. These health benefits can reduce the risk of youth suffering from type 2 diabetes and coronary heart disease. As individuals participate in more than 150 minutes per week of moderate to vigorous PA they can expect to encounter greater health benefits including: "chronic 
disease prevention, improvement of various disease biomarkers, and the maintenance of a healthy weight" (U.S. Department of Health and Human Services, 2008, A-8).

\section{Guidelines for School Physical Activity}

Increasing PA as a way to reduce overweight and obesity has become so important for Americans that when the Healthy People 2010 report was released the top two high-priority health indicators were PA and overweight and obesity, respectively. In the report the government endorses an increase in the proportion of adolescents who engage in vigorous PA that promotes cardiorespiratory fitness 3 or more days per week for 20 or more minutes per occasion (U.S. Department of Health and Human Services, 2000b). Healthy People 2010 report also set a goal to: "reduce the proportion of children and adolescents who are overweight or obese" (U.S. Department of Health and Human Services, 2000a, p.19-3). To try and achieve these goals one of the objectives of Healthy People 2010 is to: "increase to $\geq 50 \%$ the proportion of adolescents who participate in daily school physical education" (U.S. Department of Health and Human Services, 2000a, p.22-20). According to the National Association for Sport and Physical Education (2004b), children between the ages of 5-12 should accumulate a minimum of 60 minutes, and up to several hours, of age-appropriate PA on all, or most days of the week. This PA should include a mixture of moderate and vigorous PA focusing on cardiovascular strength, flexibility, and muscular strength and endurance that should be accumulated during many bouts (at least 10 minutes in duration) of PA. The National Association for Sport and Physical Education's National Standards (2004a) have been adopted by curriculum developers in many states in order to attempt to ensure that physical education teachers are teaching youth to selfassess their physical fitness in order to create PA plans that reflect that each individual needs to work on to improve his/her health. This self-assessment includes utilizing standardized criterion- 
PE Followed Me Home from School Today 51

referenced physical fitness testing. If teachers follow the National Association for Sport and Physical Education's National Standards students should be learning how to attain physical fitness, motor skills, and knowledge that will enable them to participate in a wide variety of activities, including games, sports, aquatics, and dance to attain a physically active lifestyle for a lifetime (Chow, McKenzie, \& Loui, 2008).

In accordance with the Healthy People 2010 objectives and the NASPE standards the West Virginia State Content Standards and Objectives (CSOs) for Health and Physical Education have 5 objectives that are read to include the promotion of PA. Health Standard 1 focuses on teaching basic health concepts and functional health knowledge for the purpose of promoting health-enhancing behaviors. Health Standard 5 teaches students how to effectively make decisions concerning their health to improve the quality of life. Health Standard 7 promotes the practice of health enhancing behaviors to positively influence quality of life and the prevention of disease; this standard promotes accepting personal responsibility for health and encourages the practice of healthy behaviors. The West Virginia CSOs for physical education have two standards (Standard 3: Physical Activity and Standard 4: Physical Fitness) directly related to teaching students to participate in PA for a life time in order to lead healthy lifestyles.

As indicated by Healthy People 2010, the National Association for Sport and Physical Education standards, and the West Virginia State CSOs, physical education teachers need to focus on helping students develop the attitudes, motor skills, behavior skills, and confidence they need to engage in lifelong PA (American College of Sports Medicine, 1988; Fletcher et al., 1992; American Heart Association, 1995). According to the 2006 School Health Policies and Programs study, only $3.8 \%$ of elementary schools, $7.9 \%$ of middle schools, and $2.1 \%$ of high schools provide daily physical education (Jones, et al., 2007). Too few schools are providing the 150 
PE Followed Me Home from School Today 52

minutes of physical education per week for elementary school students and 225 minutes per week for middle and secondary schools recommended by National Association for Sport and Physical Education and the West Virginia Legislature (National Association for Sport and Physical Education 2005a, 2005b; West Virginia Department of Education, 2006). One way to address this is for physical education teachers to teach students the importance of PA: how to monitor/assess it, how to manage it, and how to create interesting opportunities for participating in it, and then help the students apply it outside the classroom walls. Knowing that elementary school physical education has the potential to reach $97 \%$ of children in the United States administrators and physical education specialist need to make the most of this opportunity and find a way to teach youth the value of regular PA (Ross \& Gilbert, 1985).

\section{Strategies for Improvement: Self-Managed, Out-of-School PA Assignments}

The trend of physical inactivity in youth can be reversed. Researchers like Malina (1996) have found that children who learn leisure skills early in life increase their ability to participate in activities later in life. With that in mind, positive self-perceptions about motor skills developed by youth early in life are associated with participation in PA later in life (Fox, 2000). When educators succeed in motivating youth early in life to be physically active the chances those individuals will stay active for a lifetime increases considerably.

Many individual, interpersonal, and environmental factors contribute to an individual's decision to be physically inactive, such as: confidence in one's ability, the efficacy one feels towards exercise in general or to a specific sport, attitude toward physical education, influences of friends, siblings, parents, and teachers, economic means to pay fees or buy equipment to participate, access to PA opportunities, and access to safe locations to participate in PA. These 
factors make it necessary for physical education teachers to provide safe opportunities for students to learn about and practice different ways to accumulate PA throughout the day. It is the responsibility of the teacher to promote out of school PA that exists in the students' community. In some cases, where there are no opportunities the teacher needs to help create them. Extending PA and fitness education to out of school activities is one way to integrate health-related fitness and PA assessment into physical education. One way to extend PA outside of school is for teachers to show students how to wear and read pedometers; then, students can wear them for a designated amount of time and then the teacher can help them analyze the data to assess PA and to create a PA program (Silverman, Keating, \& Phillips, 2008). In extending physical education to out of class assignments and opportunities, teachers need to teach students how to incorporate activities that the students enjoy into their everyday PA routines; after all, if it isn't fun a student may not want to do it (McKenzie, 2003). This means physical education teachers need to teach students how to assess their PA using actual examples of activities that some of the students participate in to encourage the students to keep practicing good PA behaviors.

\section{Sports, Play \& Active Recreation for Kids}

There are programs designed for physical education teachers to promote out of school PA self-management. The Sports, Play \& Active Recreation for Kids! (SPARK) program was created to increase PA in school and out-of-school by promoting the generalization of PA. While the in school component contained lessons divided into health-fitness activities and skill-fitness activities the out-of-school component focused on goal-setting and participating in PA. The outof-school component has a weekly (30-minute) classroom-based self-management program with a specific goal of increasing PA outside of school by teaching students goal setting, behavior skills training, and includes a reward system and parental involvement. Students earn points for 
participating in out-of-school activity. Earning these points is significantly correlated with changes in BMI and multiple psychosocial variables among boys but not girls (Marcoux et al., 1999). The assessment used for the out-of-school PA component was a 1-day recall checklist. Unfortunately, with SPARK there was not an effect on student PA outside of school as verified by objective or self-assessment measures (Sallis, et al., 1997). Newer research reports that the SPARK program does affect before and after school PA but the greatest gains by far are still documented in physical education class (McKenzie et al., 2004; Sallis, et al., 2003).

The results of the SPARK program showed the program "produced students who spent more minutes per week being physically active in specialist-led (40 minutes) and teacher-led (33 minutes) physical education classes than in control classes (18min: $\mathrm{P}<.001)$ ") (Sallis, et al., 1997, p 1331). The control condition for the SPARK study suggests that, "Physical education is supplying only $18(12 \%)$ of the recommended 150 minutes of PA per school week. The teacherled condition supplied 22\%, and the specialist-led condition supplied 27\%" (Sallis, et al., 1997, p. 1331). It is startling to realize that the non-SPARK program or the average physical education program was only providing $12 \%$ of the recommended 150 minutes of PA per school week. With the amount of PA in physical education classes having such low numbers it is no wonder that students aren't learning about the generalizability of PA.

The program has barriers associated with full program implementation and it is thought that if the physical education teachers, parents, and the school administrators buy into the SPARK program fully then the students will have more positive results. Problems with implementation were attributed to: (a) general education teachers (GET) and physical education specialists (PES) only conducting 63\% and 67\% of the program components, respectively, (b) GET not collecting goal sheets or giving out rewards, (c) PES not explaining or discussing 
homework thoroughly, (d) only $26.3 \%$ of parents read most of the letters, and (e) problems with compliance for distribution of materials to parents occurred at the middle school level (Marcoux, et al., 1999). It was found that the more committed a teacher and the administration was to the SPARK program the more committed the students were and the more they participated. If implemented the correct way SPARK has a proven sustainability factor that overshadows many other programs (Ward, Saunders, \& Pate, 2007). SPARK was unique because when it was created it was designed to be used by PES or GET. Other studies have found that with proper implementation not only can girls expect to earn the same health benefits as boys but they can expect to improve in sports skills (Ward, Saunders, \& Pate, 2007).

\section{Child and Adolescent Trial for Cardiovascular Health.}

Another program that had a component that supported student self-monitoring of out-ofschool PA for elementary aged students was the Child and Adolescent Trial for Cardiovascular Health $(\mathrm{CATCH})$ program. In school components focused on teaching students healthy eating by decreasing fat and salt, increasing PA, and prevention of tobacco use to see positive influences on cholesterol, blood pressure, and physical fitness. The school lunch program also served lowerfat foods to help students learn what to eat outside of school. Students monitored their nutrition and PA at home and in school and after 3 years data indicated that high levels of participation continued through the program (Ward, Saunders, \& Pate, 2007). CATCH focused on children learning the behavior skills of self-monitoring, self-evaluation, and self-reinforcement, rather than just knowledge in order for students to learn how to incorporate all three aspects into their daily lives in order to keep them healthy. Proper training of the teachers and full support of the administration was determined as integral to the success of the CATCH program (Hoelscher et al., 2004). The three-year follow-up CATCH study examined the adherence of $73 \%$ of the initial 
program participants and found that: "Intervention students maintained significantly higher self reported daily vigourus activity than control students $(\mathrm{P}=.001)$, although the difference declined from 13.6 minutes in grade 5 to $11.2,10.8$, and 8.8 minutes in grades 6 , 7 , and 8 respectively" (Nader, et al., 1999, p. 695). This data demonstrates that physical education programs that promote out of class PA can have a lasting impact on the lives of the students who participate in such programs.

The downside to the CATCH and SPARK programs is it takes a total revision of not only the physical education department, but the health education, general education, and school policy. This requires a lot of effort on the part of all the stakeholders and unless fully implemented success cannot be guaranteed. Barriers associated with the CATCH program entailed: large class size, low priority relative to other academic subjects, inadequate financial resources, and inadequate indoor and outdoor facilities (Barroso, McCullum-Gomes, Hoelscher, Kelder, \& Murray, 2005). Because physical education is considered a low priority within schools finding means of promoting it outside of school hours has become necessary in order to ensure that today's youth are accumulating the recommended amount of PA. These out-of-school options are becoming more and more enticing because they require less professional development for teachers than both SPARK and CATCH. Utilizing out of class PA program components allow students to take advantage of community resources (parks, YMCA's, Youth Groups, and community activity clubs) in order to accumulate the recommended 60-minutes of daily PA.

Both SPARK and CATCH require a revitalization of both the instructional and curricular models of a school's physical education program. This means implementation would be a long process, but there are ways to use supplemental programs to increase youth PA without 
revamping the whole physical education program. Four of the better known, but less studied, supplemental programs are: the Presidential Active Lifestyle Award (PALA), the President's Challenge, the Presidential Champion, and Physical Best.

\section{President's Active Lifestyle Award}

The President's Council on Physical Fitness and Sports sets the standards for receiving the PALA at 60 minutes of PA a day for at least 5 days a week for a total of 6 weeks for youth (President's Council on Physical Fitness and Sport, 2003). In order to promote everyone to participate in the PALA program the program coordinators also extend the PA measurement to the use of pedometers to measure step counts, so that youth with a lower threshold for PA might make desirable progress towards PA goals at their own pace. Care was given in selecting the SPD requirements so that all youth would feel capable of attaining the goals of the program. The requirements for SPD for youth are 11,000 steps for girls and 13, 000 steps for boys. Students actually log their activity on their own time to the program website and if they meet the requirements they get a certificate signed by the President. The amount of activity required by PALA aligns with the government recommended amounts of PA of 60 minutes or more on all or most days of the week. Teachers can incorporate this program as a homework option where students bring in their logs or their certificates at the completion of the program to receive credit.

\section{President's Challenge}

The President's Challenge is a similar program to the PALA program but it has the option of letting a teacher or any adult manage a group so multiple participants can participate in the program together. This aspect is very user-friendly and any educator can do it. A physical education specialist or a general education teacher can manage a whole school through the 
PE Followed Me Home from School Today 58

website. This can also be assigned as a homework where students and their parents participate together in the program and the parents can register their activity along with the students'.

Teachers can incorporate this program as a homework option for students to bring in their logs or their certificates at the completion of the program to receive credit. Teachers can also use this as an in school assignment where students record their activity daily at school. The teacher can provide ideas for activities or even have and after school program set up to supervise students who do not have a safe/supervised home setting for them to participate.

\section{Presidential Champions}

The President's Challenge also houses the Presidential Champions program. This program was designed for already active youth and assigns points to activities based on how hard the activity forces the participant to work, also known as energy expenditure (President's Council on Physical Fitness and Sport, 2007). The Champions program is stratified by Bronze, Silver, and Gold levels to allow for more progression and goal achievement over a longer period of time. The President's Challenge and the Presidential Champions programs were created to allow students to progress through differing levels of PA. They were also designed to let participants work at appropriate levels in order to let each individual feel challenged with the activity level $\mathrm{s} /$ he decides to participate at. This program cannot be managed by a teacher as the President's Challenge can, but would be easy to incorporate like the PALA program. All three of the President's programs can be incorporated by a general education teacher or a physical education specialist in a way that does not take a lot of time away from an already busy curriculum. 
PE Followed Me Home from School Today 59

\section{Physical Best}

Meanwhile, the Physical Best program was specifically designed to give teachers a variety of fun fitness activities that students could participate in to help teach fitness effectively (National Association for Sport and Physical Education, 2005 a, b). The Physical Best program includes: ways of motivating students to be active, ways to teach students about the importance of monitoring and working towards healthy levels of aerobic fitness, muscular strength and endurance, flexibility, and body composition, Health-Related Physical Fitness Education, nutrition, assessment, and ways to draw students into participating in PA. The Physical Best inschool program has criterion referenced health zones set for: aerobic fitness, muscular strength and endurance, flexibility, and body composition. These health zones set attainable age appropriate goals for students to try and achieve to improve the quality of their health.

One of the Physical Best's out-of-school components is the Summer Shape-Up Challenge. The Summer Shape-Up Challenge program challenges student to participate in structured categories of PA over summer break. The aim of the Summer Shape-Up Challenge is to keep student activity levels up while they are not enrolled in school and able to participate in physical education class. During the program, students will be introduced to six activity categories and they will have the option to choose which activities they will participate in during the summer break. The activity categories include: (a) Vacation Run, (b) Wheels in Motion, (c) Swim Like an Olympian, (d) Parents Like to Play Too, (e) Try Something New, and (f) Keep the Log Rolling. Students are told to participate in three of the six different categories of PA for the summer. The students log their activity in the categories over the course of the summer on paper logs. When the students return to school in the fall they turn in their sheets and the teacher checks to see which students participated in three categories for the duration of the summer. For 
the Vacation Run, students will select a relative or friend to visit in a nearby town, determine the distance to their house, draw a map to plot the course of the trip, run or walk this trip distance over the course of the summer, and log and chart the mileage (using a pedometer) until they reach their destination. For Wheels in Motion, students will use a bike, scooter, roller skates, inline skates, or skateboard and challenge themselves to $\log 20$ miles during the course of the summer and will record the date and distance they travel. Swim Like an Olympian involves the students trying to swim 2 miles by the end of the summer. Parents Like to Play Too involves participating with one or both parents/guardians one day per week, every week of the summer, for at least 20 minutes in some sort of PA. Try Something New challenges the students to participate in an activity they have not tried before and participate at least six times in that activity over the summer logging the dates and time spent. Keep the Log Rolling involves the students keeping a log of their favorite activities and challenges them to participate in three activities a week for 20 minutes in duration while recording date and time spent being active.

While it is speculated that aligning the goals of the Physical Best Summer Shape-Up Challenge with the government recommended 60 minutes of PA daily for youth the out-ofschool components will lead to the accumulation of appropriate amounts of daily PA the Summer Shape-Up Challenge has not been studied enough to see if students will have positive physical health benefits from the time and type of activity required. Because PALA and Physical Best Summer Shape-Up Challenge require the activities to take place completely out-of-school they will encroach on less curricular time and require smaller curricular changes to implement them than the SPARK and CATCH programs. As observed from the SPARK and CATCH data some of the key components a program needs in order to be effective are: dedication to the program by the administration of the school and enthusiasm and commitment by the physical 
education teacher. Further research is needed to asses if health benefits can be achieved by participants following either out-of-school program.

PA is directly related to the health and safety of every individual, as such, it should be treated in the same way as anti-smoking and anti-drinking campaigns, as preventative measures. Increasing PA while simultaneously decreasing sedentary activity is directly related to the prevention of disease and the maintenance of a healthy body; if America's youth are not informed of the importance of PA in school and given ways to participate in it out of school then risk factors associated with physical inactivity may rise to the level of the adverse health effects of tobacco. Teachers need to teach students how to be physically active during the school day and promote and help students monitor PA outside of the school. Teaching students how to be active outside of the school walls will help the students develop an independent attitude toward PA that will extend into their adult lives. Providing opportunities for students to learn to access and utilize PA opportunities today will positively affect the future attitudes students will have towards PA. The youth of today must be taught how to track their PA in order to promote the most positive health-related outcomes possible in order to ensure that they will have healthy futures. Structured out-of-school assignments can teach students the importance of: being active, tracking PA, and accessing fun and effective ways to perform PA. 
APPENDIX C

ADDITIONAL MATERIALS
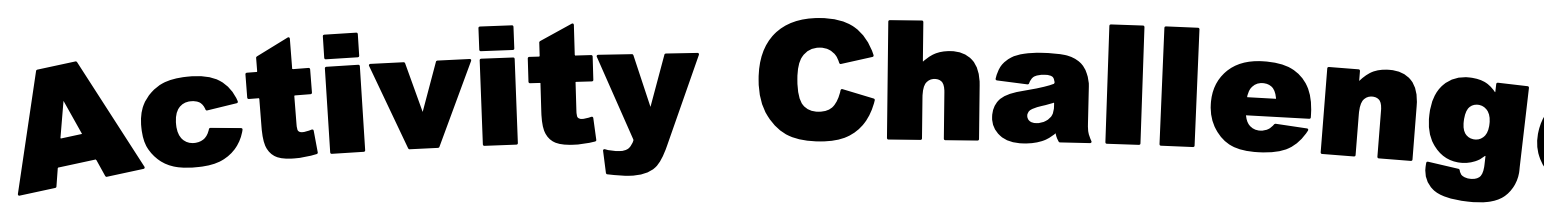

2

We are offering a take-home summer physical activity

program for $3^{\text {rd }}, 4^{\text {th }}$, and $5^{\text {th }}$ grade students. If you participate in the program and complete the challenge you will get:

- A Program Completion Certificate

o A AC t-shirt

- An Activity Pack

- Your picture in the local newspaper

What you have to do is easy. Just complete 3 of the activity challenges on the back of this sheet this summer.

There will be a mandatory Kick-off event on June $12^{\text {th }}$ at 6:30PM at the school where you and your parents/guardians will be told the rules of the program and what you have to do to earn your certificate.

Have fun this summer; play, exercise, try new things, and win prizes all while improving your health.

If you are interested in participating in the program please turn in your registration form to your homeroom teacher by May $30^{\text {th }}$. 


\section{Activity Challenge}

In order to earn the Activity Challenge certificate, you will need to complete Tune Out plus 2 of the 5 other activity challenges.

\section{Tune Out}

To complete this challenge you need to decrease the amount of time you spend in front of the TV, computer, or video game screen during non-educational activities. Limit your time with the TV, computer, and video games to 2 hours a day for the whole program.

\section{Wheels in Motion}

Using your bike, scooter, roller skates, in-

line skates or skateboard, challenge

yourself to $\log 20$ miles between the program start date and the program end date.

\section{The Vacation Run}

Select a relative or friend you'd like to visit who lives in a nearby town. Determine the distance to their house. Draw a map to plot the course of your trip. As you run or walk this distance, log and chart your mileage until you've reached your destination.
2. Parents Like to Play, Too

To complete this challenge, you must participate with one or both parents or guardians at least 1 day per week for 6 weeks. Your activity session should be at least 20 minutes long.

\section{Try Something New}

The challenge is for you to participate in an activity you have not tried before. Find a friend or family member to help teach you necessary skills to complete this challenge. Participate at least 5 more times during the program and log the dates and time spent.

\section{Keep the Log Rolling}

Keep a log of your favorite activities. Challenge yourself to three activities a week at 20 minutes in duration. Record date and time spent. Suggested activities:

ballet, basketball, baseball or teeball, bowling, golf, gymnastics, hiking, jogging, hula hoop, jump rope, karate, playing catch, soccer, tennis, dance class, waterskiing, and wrestling. 


\section{Activty Challenge}

Registration Form

Student's name:

Grade:

Student's address:

Student's home phone number:

Do you have access to a computer with internet access daily? Yes No

I would like to participate in the Activity Challenge: Yes No

Parent/Guardian's name:

Parent/Guardian's address:

Perent/Guardian's phone number (most appropriate for contating you):

Will you likely permit your child/ward to participate in this summer program after attending the mandatory orientation meeting on June $12^{\text {th }}$ at $6: 30 \mathrm{PM}$ at the school. 


\section{AC Activity Log}

Name:

\begin{tabular}{|c|c|c|c|c|c|c|}
\hline Date & $\begin{array}{c}\text { Challenge } \\
\#\end{array}$ & Activity & Time/Distance & Intensity & $\begin{array}{l}\text { Daily } \\
\text { Steps }\end{array}$ & $\begin{array}{c}\text { Daily Screen } \\
\text { Time }\end{array}$ \\
\hline $6 / 14$ & 2 & $\begin{array}{l}\text { Went on a hike } \\
\text { with dad }\end{array}$ & 30 minutes & Moderate & 12,000 & 30 minutes \\
\hline & & & & & & \\
\hline & & & & & & \\
\hline & & & & & & \\
\hline & & & & & & \\
\hline & & & & & & \\
\hline & & & & & & \\
\hline & & & & & & \\
\hline & & & & & & \\
\hline & & & & & & \\
\hline & & & & & & \\
\hline & & & & & & \\
\hline & & & & & & \\
\hline
\end{tabular}

Intensity

Easy- easier to do than walking

Moderate- like normal walking

Hard- more than normal walking but less than very hard

Very Hard- I was out of breath by the time I was done with this activity 


\section{AC Parent Proxy Report}

1. On how many of the past 7 days did your child exercise or take part in physical activity that made his/her heart beat fast and made him/her breathe hard for at least 20 minutes? (For example: basketball, soccer, running or jogging, fast dancing, swimming laps, tennis, fast bicycling, or similar aerobic activities).

0 days

1 day

2 days

3 days

4 days

5 days

6 days

7 days

2. On how many of the past 7 days did your child do an exercise that did not make his/her heart beat fast and did not make him/her breathe hard for at least 30 minutes? (For example: fast walking, slow bicycling, skating, pushing a lawn mower, or mopping floors.)

0 days

1 day

2 days

3 days

4 days

5 days

6 days

7 days

3. On how many of the past 7 days did your child do exercises to strengthen or tone his/her muscles? This includes exercises such as push-ups, sit-ups, or weightlifting.

0 days

1 day

2 days

3 days

4 days

5 days

6 days

7 days 
4. On how many of the past 7 days did your child do stretching exercises to loosen up or relax his/her muscles? This includes exercises such as toe touches, knee bending, or leg stretching.

0 days

1 day

2 days

3 days

4 days

5 days

6 days

7 days

5. During the past 7 days, did you or another parent/guardian participate in physical activity with your child at least 1 day for 20 minutes or more?

Yes No

6. During the past 7 days, has your child ridden a bike, scooter, skateboard, roller skates, or roller blades?

Yes No

7. During the past 7 days, has your child participated in a new activity he/she has never tried before?

Yes No

8. During the past 7 days, has your child walked or ran for bouts of 10 minutes or more?

Yes No

9. During the past 7 days, did any of your child's physical activity take place because of a sports team? Sports teams include: soccer, basketball, baseball, softball, swimming, gymnastics, cheerleading, wrestling, track, football, dance, tennis, and volleyball teams.

Yes No

10. During the past 7 days did your child take part in any other organized physical activities or take lessons, such as martial arts, dance, gymnastics, or tennis?

Yes No 
11. Yesterday, how many hours did your child watch TV or video movies?

My child didn't watch TV yesterday

1 hour

2 hours

3 hours

4 hours

5 hours

6 hours or more

12. During the past 7 days about how many hours per day did your child spend on the computer engaged in non-school related activities?

(Time on the computer includes time spent surfing the Internet and instant messaging.)

My child doesn't use the computer

1 hour

2 hours

3 hours

4 hours

5 hours

6 hours or more

13. During the past 7 days about how many hours per day did your child spend playing video games like Nintendo ${ }^{\circledR}$, Sega ${ }^{\circledR}$, PlayStation ${ }^{\circledR}, X$ box ${ }^{\circledR}$, GameBoy ${ }^{\circledR}$ or arcade games?

My child doesn't play video games

1 hour

2 hours

3 hours

4 hours

5 hours

6 hours or more 


\section{AC Student Survey}

1. On how many of the past 7 days did you exercise or take part in physical activity that made your heart beat fast and made you breathe hard for at least 20 minutes? (For example: basketball, soccer, running or jogging, fast dancing, swimming laps, tennis, fast bicycling, or similar aerobic activities).

0 days

1 day

2 days

3 days

4 days

5 days

6 days

7 days

2. On how many of the past 7 days did you do an exercise that did not make your heart beat fast and did not make you breathe hard for at least 30 minutes? (For example: fast walking, slow bicycling, skating, pushing a lawn mower, or mopping floors.)

0 days

1 day

2 days

3 days

4 days

5 days

6 days

7 days

3. On how many of the past 7 days did you do exercises to strengthen or tone your muscles? This includes exercises such as push-ups, sit-ups, or weightlifting.

0 days

1 day

2 days

3 days

4 days

5 days

6 days

7 days 
4. On how many of the past 7 days did you do stretching exercises to loosen up or relax your muscles? This includes exercises such as toe touches, knee bending, or leg stretching.

0 days

1 day

2 days

3 days

4 days

5 days

6 days

7 days

5. During the past 7 days, did you participate in physical activity with 1 or both parents/guardians for at least 1 day for 20 minutes or more?

Yes No

6. During the past 7 days, have you ridden a bike, scooter, skateboard, roller skates, or roller blades?

Yes No

7. During the past 7 days, have you participated in a new activity you have never tried before?

Yes No

8. During the past 7 days, have you walked or ran for bouts of 10 minutes or more?

Yes No

9. During the past 7 days did any of your physical activity take place because of a sports team? Sports teams include: soccer, basketball, baseball, softball, swimming, gymnastics, cheerleading, wrestling, track, football, dance, tennis, and volleyball teams.

Yes No

10. Do you currently take part in any other organized physical activities or take lessons, such as martial arts, dance, gymnastics, or tennis?

Yes No

11. Yesterday, how many hours did you watch TV or video movies?

I didn't watch TV yesterday

1 hour

2 hours

3 hours

4 hours

5 hours

6 hours or more 
12. During the past 7 days, how many hours per day do you usually spend on the computer away from schoolwork?

(Time on the computer includes time spent surfing the Internet and instant messaging.)

I don't use the computer

1 hour

2 hours

3 hours

4 hours

5 hours

6 hours or more

13. During the past 7 days, how many hours per day do you usually spend playing video games like Nintendo ${ }^{\circledR}$,

Sega ${ }^{\circledR}$, PlayStation ${ }^{\circledR}$, Xbox ${ }^{\circledR}$, GameBoy ${ }^{\circledR}$ or arcade?

I don't play video games

1 hour

2 hours

3 hours

4 hours

5 hours

6 hours or more 


\section{Definitions and Alternate Terms}

- Physical Activity- any movement produced by skeletal muscles that results in the use of energy

- Aerobic- The ability to exercise or play for long periods of time using large muscle groups able to work the heart and lungs to help the body use oxygen better: exercise, such as jogging, swimming, or cycling

- Weightlifting- lifting heavy weights in a prescribed manner

- Stretching-to spread out or reach out to the full length in order to make loose and flexible.

- Strengthening- to make or grow strong or stronger

- Exercise- physical activity that is planned, structured, and repetitive bodily movement done to improve your health. activity done to keep the body strong or to make them stronger.

- Martial Arts- Asian arts of combat or self-defense, such as aikido, karate, judo, or tae kwon do, usually practiced as sport

- Gymnastics- exercises designed to develop and display strength, balance, and agility, especially those performed on or with specialized apparatus 


\section{Qualitative Questions}

1. What did you like about the Activity Challenge?

2. What part of the Activity Challenge didn't you like?

3. What could we change to make the Activity Challenge more fun for you to complete?

4. What kept you from fully participating in the Activity Challenge? 
AC Activity Log

Name:

\begin{tabular}{|c|c|c|c|c|c|}
\hline Date & Activity & Time/Distance & Intensity & Daily Steps & Daily Screen Time \\
\hline $6 / 14$ & Went on a hike with dad & 30 minutes & Moderate & 12,000 & 30 minutes \\
\hline & & & & & \\
\hline & & & & & \\
\hline & & & & & \\
\hline & & & & & \\
\hline & & & & & \\
\hline & & & & & \\
\hline & & & & & \\
\hline & & & & & \\
\hline & & & & & \\
\hline & & & & & \\
\hline & & & & & \\
\hline & & & & & \\
\hline & & & & & \\
\hline & & & & & \\
\hline
\end{tabular}

Intensity

Easy- easier to do than walking

Moderate- like normal walking

Hard- more than normal walking but less than very hard

Very Hard- I was out of breath by the time I was done with this activity 


\section{ABABC Group}

Activity Challenge

In order to earn the Activity Challenge certificate, I will complete Tune Out plus 2 of the 5 other activity challenges.

Student Signature

\section{Tune Out}

To complete this challenge you need to decrease the amount of time you spend in front of the TV, computer, or video game screen during non-educational activities. Limit your time with the TV, computer, and video games to 2 hours a day for the whole program.

\section{Wheels in Motion}

Using your bike, scooter, roller skates, inline skates or skateboard, challenge yourself to $\log 20$ miles between the program start date and the program end date.

\section{The Vacation Run}

Select a relative or friend you'd like to visit who lives in a nearby town. Determine the distance to their house. Draw a map to plot the course of your trip. As you run or walk, log and chart your mileage until you've reached your destination.
Parent/ Guardian Signature

\section{Parents Like to Play, Too}

To complete this challenge, you must participate with one or both parents or guardians at least 1 day per week for 6 weeks. Your activity session should be at least 20 minutes long.

\section{Try Something New}

The challenge is for you to participate in an activity you have not tried before. Find a friend or family member to help teach you necessary skills to complete this challenge. Participate at least 5 more times during the program and log the dates and time spent.

\section{Keep the Log Rolling}

Keep a log of your favorite activities. Challenge yourself to three activities a week at 20 minutes in duration. Record date and time spent. Suggested activities: ballet, basketball, baseball or teeball, bowling, golf, gymnastics, hiking, jogging, hula hoop, jump rope, karate, playing catch, soccer, tennis, dance class, waterskiing, and wrestling. 


\section{Activity Challenge}

In order to earn the Activity Challenge certificate, I will complete Tune Out plus 2 of the 5 other activity challenges.

Student Signature

\section{1. Tune Out}

To complete this challenge you need to decrease the amount of time you spend in front of the TV, computer, or video game screen during non-educational activities. Limit your time with the TV, computer, and video games to 2 hours a day for the whole program.

\section{Wheels in Motion}

Using your bike, scooter, roller skates, inline skates or skateboard, challenge yourself to $\log 10$ miles between the program start date and the program end date.

\section{The Vacation Run}

Select a relative or friend you'd like to visit who lives in a nearby town. Determine the distance to their house. Draw a map to plot the course of your trip. As you run or walk, log and chart your mileage until you've reached your destination.
Parent/ Guardian Signature

2. Parents Like to Play, Too

To complete this challenge, you must participate with one or both parents or guardians at least 1 day per week for 3 weeks. Your activity session should be at least 20 minutes long.

\section{Try Something New}

The challenge is for you to participate in an activity you have not tried before. Find a friend or family member to help teach you necessary skills to complete this challenge. Participate at least 2 more times during the program and log the dates and time spent.

\section{Keep the Log Rolling}

Keep a log of your favorite activities. Challenge yourself to three activities a week at 20 minutes in duration. Record date and time spent. Suggested activities: ballet, basketball, baseball or teeball, bowling, golf, gymnastics, hiking, jogging, hula hoop, jump rope, karate, playing catch, soccer, tennis, dance class, waterskiing, and wrestling. 


\section{APPENDIX D \\ WVOM SCHOOLS ON THE MOVE GRANT}

The first program is the Summer Shape-Up Challenge which is a family-based

intervention and will take place from June-August 2009. The program will involve 6 components intended to promote student physical activity during summer break. This assignment will be marketed as a summer physical activity assignment, much like a summer reading assignment, and will follow the example of the NASPE Physical Best Summer Shape-Up Challenge. The objective will be to help $3^{\text {rd }}, 4^{\text {th }}$, and $5^{\text {th }}$ grade students maintain or increase physical activity in order to achieve the FITNESSGRAM Healthy-Fitness Zones for body mass index (BMI) and aerobic fitness (PACER test), while reducing time spent in more sedentary pursuits. A second objective will be to teach students to monitor their own physical activity behavior. Students will be given 6 activity categories and they will have the option to choose which they will participate in during the summer break. Those activities will be: (a) Vacation Run, (b) Wheels in Motion, (c) Swim Like an Olympian, (d) Parents Like to Play Too, (e) Try Something New, and (f) Keep the Log Rolling. Students will be asked to participate in 3 of 6 different categories of physical activity for the summer. Students will define their participation in these categories as: easy (easier to do than walking), moderate (like normal walking), hard (more than normal walking but less than very hard), and very hard (was out of breath by the time I got done with the activity). If the students participate in the required amount of physical activity they will receive an incentive: individual certificates, t-shirts, name listed in the paper, and prizes for successfully completing 3 activity categories. To evaluate program effectiveness, physical activity data relating to frequency, intensity, time, and type (FITT) will be collected through the program website. Students will learn how to enter their information on to the school's physical education website by entering: their name, the activity category in which they participated, the amount of time they 
were active, their activity level, and how far they went or what specifically they did (dependent upon which activity category they choose to participate in). The students will also complete periodic attitudinal surveys and physical activity recall questionnaires so that the program coordinators can assess if the students were more active than usual and what worked and what didn't work within the program. Pre- and post-test data relating to students' aerobic fitness and BMI will be collected to see if the students improved or maintained health-related fitness during the summer. The full grant application is available by clicking on the following link.

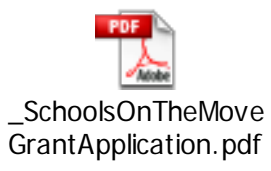


PE Followed Me Home from School Today 79

\section{APPENDIX E \\ ADDITIONAL REFERENCES}

Ainsworth, B.E., Haskell, W.L., Leon, A.S., Jacobs, D.R. Jr., Montoye, H.J., Sallis, J.F., \& Paffenbarger, R.S. Jr. (1993). Compendium of physical activities: Classification of energy costs of human physical activities. Medicine and Science in Sports and Exercise, 25,71-80.

American Academy of Pediatrics. (1987). Physical fitness and the schools. Pediatrics, 80, 449450.

American Academy of Pediatrics. (2003). Prevention of pediatric overweight and obesity. Retrieved October 29, 2008, from http://www.pediatrics.org/cgi/content/full/112/2/424

American College of Sports Medicine. (1988). Opinion statement on physical fitness in children and youth. Medicine \& Science in Sports \& Exercise, 20, 422-423.

American Heart Association. (1995). Strategic plan for promoting physical activity. Dallas, TX: Author.

American Heart Association. (2005). A Nation at Risk: Obesity in the United States. [Statistical Sourcebook]. Dallas, TX: Author.

Baer, D.M. (1977). Perhaps it would be better not to know everything. Journal of Applied Behavior Analysis, 10, 167-172.

Barroso, C.S., McCullum-Gomes, C., Hoelscher, D.M., Kelder, S.H., \& Murray, N.G. (2005). Self-reported barriers to quality physical education by physical education specialists in Texas. Journal of School Health, 75, 313-319.

Bassett, D.R. Jr., \& Strath, S.J. (2002). Use of Pedometers to Assess Physical Activity. In G.J. Welk (Eds.), Physical activity assessments for Health-Related Research (pp. 163-177). Champaign, IL: Human Kinetics.

Bauer, K.W., Nelson, M.C., Boutelle, K.N., \& Neumark-Sztainer, D. (2008). Parental influences on adolescents' physical activity and sedentary behavior: Longitudinal findings from Project EAT-II. International Journal of Behavior Nutrition \& Physical Activity, 5(12), $1-7$.

Cardon, G., \& De Bourdeaudhuij, I. (2007). Comparison of pedometer and accelerometer measures of physical activity in preschool children. Pediatric Exercise Science, 19, $205-$ 214.

Caspersen, C.J., Powell, K.E., \& Christenson, G.M. (1985). Physical activity, exercise, and physical fitness: Definitions and distinctions for health-related research. Public Health Reports, 100: 126-131. 
Centers for Disease Control and Prevention. (1997). Guidelines for school and community programs to promote lifelong physical activity among young people. MMWR, 46 (No. RR-6), 1-35.

Centers for Disease Control and Prevention. (2003). National Survey of Children's Health, 2003: State and Local Area Integrated Telephone Survey. Retrieved April 20, 2009, from http://www.cdc.gov/nchs/about/major/slaits/nsch.htm

Centers for Disease Control and Prevention (2008a). Behavioral Risk Factor Surveillance System Survey Data. Atlanta, Georgia: U.S. Department of Health and Human Services, Centers for Disease Control and Prevention.

Centers for Disease Control and Prevention. (2008b). Comparison Between West Virginia Students and U.S. Students 2007 Youth Risk Behavior Survey. Retrieved November 8, 2008, from

http://www.cdc.gov/HealthyYouth/yrbs/pdf/states/yrbs07_west_virginia_us_comparison. pdf

Centers for Disease Control and Prevention. (2008c). U.S. Obesity Trends 1985-2007. Retrieved March 1, 2009, from http://www.cdc.gov/nccdphp/dnpa/obesity/trend/maps/index.htm

Chow, B.C., McKenzie, T.L., \& Loui, L. (2008). Children's physical activity and environmental influences during elementary school physical education. Journal of Teaching in Physical Education, 27, 38-50.

Coordinated Approach to Child Health. (2004). School Physical activity and Nutrition (SPAN) Questionnaire. Retrieved April 2, 2009, from http://www.sph.uth.tmc.edu/catch/catch_em/MeasureToolsDesc_01.htm

Dennison, B.A., Straus, J.H., Mellits, E.D., \& Charney, E. (1988). Childhood physical fitness tests: Predictor of adult physical activity levels? Pediatrics, 82, 323-330.

Ferrera, L. (2005). Body mass index: New research. Hauppauge, NY: Nova Publishers.

Fletcher, G.F., Blair, S.N., Blumenthal, J., Caspersen, C., Chaitman, B., Epstein, S., et al. (1992). Statement on exercise. Benefits and recommendations for physical activity programs for all Americans. Circulation, 86, 340-344.

Fox, K.R. (2000). The effects of exercise on physical self-perceptions and self-esteem. In S. J. H. Biddle, K. R. Fox, and S. H. Boutcher (Eds), Physical activity and psychological wellbeing (pp. 88-117). London: Routledge.

Freedman D.S., Dietz, W.H., Srinivasan, S.R., \& Berenson, G.S. (1999). The relation of overweight to cardiovascular risk factors among children and adolescents: the Bogalusa heart study. Pediatrics, 103, 1175-1182.

Fulton, J.E., Meenakshi, G., Galusk, D.A., Rattay, K.T., \& Caspersen, C.J., (2004). Public health and clinical recommendations for physical activity and physical fitness: Special focus on overweight youth. Sports Medicine, 34, 581-599. 
Gidding, S.S, Bao, W., Srinivasan, S.R., \& Berenson, G.W. (1995). Effects of secular trends in obesity on coronary risk factors in children: the Bogalusa heart study. Journal of Pediatrics, 127, 868-874.

Hancox, R., Milne, B., \& Poulton, R. (2004). Association between child and adolescent television viewing and adult health: A longitudinal birth cohort study. The Lancet, 364, 257-262.

Hoelscher, D.M., Feldman, H.A., Johnson, C.C., Lytle, L.A., Osganian, S.K., Parcel, G.S, et al. (2004). School-based health education programs can be maintained over time: Results from the CATCH Institutionalization study. Preventive Medicine, 38, 594-606.

Hughes, A.R., \& Reilly, J.J. (2008). Disease management programs targeting obesity in children: Setting the scene for wellness in the future. Disease Management and Health Outcomes, $16,255-266$.

Jones, S.E., Axelrad, R., \& Wattigney, W.A. (2007). Healthy and safe school environment, part II, physical school environment: Results from the school health policies and programs study 2006. Journal of School Health, 77, 544-556.

Kazdin, A.E. (1982). Single-case research designs. New York, NY: Oxford University Press.

Le Masurier, G.C., Beighle, A., Corbin, C.B., Darst, P.W., Morgan, C., Pangrazi, R.P., et.al. (2005). Pedometer-determined physical activity levels or youth. Journal of Physical Activity and Health, 2, 159-168.

Marcoux, M-F., Sallis, J.F., McKenzie, T.L., Marshall, S., Armstrong, C.A., \& Goggin, K.J. (1999). Process evaluation of a physical activity self-management program for children: SPARK. Psychology and Health, 14, 659-677.

Malina, R.M. (1996). Tracking of physical activity and physical fitness across the lifespan. Research Quarterly for Exercise and Sport, 67, 48-57.

McGinnis, J.M., \& Foege, W.H. (1993). Actual causes of death in the United States. Journal of the American Medical Association, 270, 2207-2212.

McKenzie, T.L. (2003). Health-related physical education: Physical activity, fitness, and wellness, In S.J. Silverman \& C.D. Ennis (Eds.), Student learning in physical education: Applying research to enhance instruction ( $2^{\text {nd }}$ ed., pp. 207-226). Champaign, IL: Human Kinetics.

McKenzie, T.L., Sallis, J.F., Prochaska, J.J., Conway, T.L., Marshall, S.J., \& Rosengard, P. (2004). Evaluation of a 2-year middle school physical education intervention: M-SPAN. Medicine and Science in Sports and Exercise, 36, 1382-1388.

Meredith, MD \& GJ Welk. FITNESSGRAM / ACTIVITYGRAM Test Administration Manual (4th ed.) . Champaign, IL: Human Kinetics, 2007.

Michael, J. (1974). Statistical inference for individual organism research: Mixed blessing or cures? Journal of Applied Behavior Analysis, 9, 127-139. 
Nader, P.R., Stone, E.J., Lytle, L.A., Perry, C.L., Osganian, S.K., Kelder, S., et al. (1999). Threeyear maintenance of improved diet and physical activity: The CATCH cohort. Archives of Pediatric and Adolescent Medicine, 153, 695-704.

National Association for Sport and Physical Education. Moving into the Future: National Standards for Physical Education, 2nd Edition. Retrieved March 1, 2009, from http://www.aahperd.org/naspe/template.cfm?template=publicationsnationalstandards $3 . \mathrm{html}$

National Association for Sport and Physical Education. (2002). Active Start: A statement of physical activity guidelines for children birth to five years, Reston, VA: American Alliance for Health, Physical Education, Recreation and Dance: Author.

National Association for Sport and Physical Education. (2004a). National standards for beginning physical education teachers ( $2^{\text {nd }}$ ed.). Reston, VA: National Association for Sport and Physical Education Publications

National Association for Sport and Physical Education. (2004b) Physical activity for children: A Statement of guidelines for children ages 5-12 ( $2^{\text {nd }}$ ed.). Reston, VA: National Association for Sport and Physical Education Publications

National Association for Sport and Physical Education. (2005a). Physical Best activity guide: Elementary level ( $2^{\text {nd }}$ ed.). Champaign, IL: Human Kinetics.

National Association for Sport and Physical Education. (2005b). Physical Best activity guide: Middle and high school levels ( $2^{\text {nd }}$ ed.). Champaign, IL: Human Kinetics.

National Association for Sport and Physical Education. (2005c). Physical education for lifelong fitness: Physical Best teacher's guide (2 ${ }^{\text {nd }}$ ed.). Champaign, IL: Human Kinetics

Pate, R.L., Davis, M.G., Robinson, T.N., Stone, E.J., McKenzie, T.L., \& Young, J.C. (2006). Promoting physical activity in children and youth: A leadership role for schools: A scientific statement from the American Heart Association Council on Nutrition, Physical Activity, and Metabolism (Physical Activity Committee) in collaboration with the Councils on Cardiovascular Disease in the Young and Cardiovascular Nursing. Circulation, 114, 1214-1224. Retrieved September 18, 2006, from http://circ.ahajournals.org/cgi/content/full/114/11/1214

President's Council on Physical Fitness and Sport. (2003). The President's Challenge Physical activity and physical fitness awards program. Bloomington, IN: The President's Council on Physical Fitness and Sports, United States Department of Health and Human Services.

President's Council on Physical Fitness and Sport. (2007). President's challenge: Physical activity and fitness award program (2001-2002). Retrieved December 1, 2008, from http://www.fitness.gov/challenge/challenge.html.

The President's Challenge. The President's Active Lifestyle Program. Retrieved March 1, 2010, from http://www.presidentschallenge.org/the_challenge/active_lifestyle_rules.aspx 
Rideout, V.J., Foehr, U.G., Roberts, D.F., \& Brodie, M. (1999). Kids \& media @ the new millennium [monograph]. Menlo Park, CA: Kaiser Family Foundation.

Robinson, T.N. (1999). Reducing children's television viewing to prevent obesity: A randomized controlled trial. Journal of the American Medical Association. 282, 1561-1567.

Ross, J.G., \& Gilbert, G.G. (1985). The national children and youth fitness study: A summary of findings. Journal of Physical Education, Recreation, and Dance, 56(1), 45-50.

Sallis, J.F., Mackenzie, T.L., Alcaraz, J.E., Koldy, B., Faucette, N., \& Hovell, M.F. (1997). The effects of a 2-year physical education program (SPARK) on physical activity and fitness in elementary school students. American Journal of Public Health, 87, 1328-1334.

Sallis, J.F., McKenzie, T.L, Conway, T.L., Elder, J.P., Porchaska, J.J. Brown, M., et al. (2003). Environmental interventions for eating and physical activity: A randomized controlled trial in middle schools. American Journal of Preventive Medicine, 23, 209-217.

Sallis, J.F., McKenzie, T.L., Kolody, B., Lewis, M., Marshall, S., \& Rosengard, P. (1999). Effects of health-related physical education on academic achievement: project SPARK. Research Quarterly for Exercise and Sport, 70, 127-34.

Silverman, S., Keating, X.D., \& Phillips, S.R. (2008). A lasting impression: A pedagogical perspective on youth fitness testing. Measurement in Physical Education and Exercise Science, 12, 146-166.

Troiano, R.P., Flegal, K.M., Kuczmarksi, R.J., Campbell, S.M., \& Johnson, C.L. (1995). Overweight prevalence and trends for children and adolescents. Archives of Pediatric \& Adolescent Medicine, 149, 1085-1091.

United States Department of Health and Human Services. (1980). Promoting health/preventing disease: Objectives for the nation. Washington, DC: United States Government Printing Office.

U.S. Department of Health and Human Services. (1996). Physical activity and health: A report of the Surgeon General. Atlanta, GA: U.S. Department of Health and Human Services, Centers for Disease Control and Prevention, National Center for Chronic Disease Prevention and Health Promotion.

U.S. Department of Health and Human Services. (2000a). Healthy people 2010: Understanding and improving health ( $2^{\text {nd }}$ ed.). Washington, DC: United States Government Printing Office

U.S. Department of Health and Human Services. (2000b). Promoting better health for young people through physical activity and sports. Atlanta, GA: United States Department of Health and Human Services and Department of Education.

U.S. Department of Health and Human Services. (2008). Physical Activity Guidelines Advisory Committee. Washington, DC: U.S. Government Printing Office. 
Ward, D.S., Saunders, R.P., \& Pate, R.R. (2007). Physical activity interventions in children. Champaign, IL: Human Kinetics.

West Virginia Department of Education. (2006). WVBOE takes a strong stance on student wellness. Retrieved February 28, 2009, from http://wvde.state.wv.us/news/1177/

West Virginia Department of Education. (2008). 2007 West Virginia Middle School Youth Risk Behavior Survey Results: Executive Summary. Retrieved November 9, 2008, from http://wvde.state.wv.us/osshp/main/programs.html

West Virginia Department of Health and Human Resources Bureau for Public Health. (2007). 2004-2005 West Virginia Behavioral Risk Factor Survey Report. Retrieved November 8, 2008 from http://www.wvdhhr.org/bph/oehp/hsc/pubs/BRFSS2004and2005/default.htm

West Virginia University. (2008, Fall). Impact. Retrieved November 8, 2008, from the West Virginia University Health Science Center Web site: http://prc.hsc.wvu.edu/pdfs/fallnews.pdf

Wolf, M.M. (1978). Social validity: The case for subjective measurement or how applied behavior analysis is finding its Heart. Journal of Applied Behavior Analysis, 11, 203-214.

Zill, N., Nord, C.W., \& Loomis, L.S. (1995). Adolescent time use, risky behavior and outcomes: an analysis of national data. Rockville, MD: Westat. 


\section{Kacey Lynn DiGiacinto}

\section{SUMMARY OF QUALIFICATIONS:}

- Dedicated to professional development as demonstrated by professional membership, conference presentations, attendance, and attainment of a second master's degree in School Health Education

- Wide range of college teaching responsibilities including educational psychology, pedagogy, curriculum and instruction, fitness education, activity, and pedagogical content knowledge courses

- Background in the area of scholarship includes experience with grant-writing, fund-raising, survey research methods, and single-case design

- Service oriented as demonstrated by design and implementation of physical activity programming at the elementary school level, work with the American Red Cross, and swim lesson instruction

\section{EDUCATION:}

Doctor of Philosophy in Kinesiology

2010

West Virginia University, Morgantown, WV

Emphasis: Physical Education Teacher Education

Cognate Area: School Health Education/Community Health

Dissertation Topic: Out-of-School Elementary Physical Activity Programming

Master of Science in School Health Education

2009

West Virginia University, Morgantown, WV

Master of Arts in Secondary Education

2007

West Virginia University, Morgantown, WV

Bachelor of Arts in English

2005

West Virginia University, Morgantown, WV

\section{HONORS AND AWARDS:}

West Virginia University, College of Physical Activity and Sports Sciences, 2008-2009 Physical Education Teacher Education Outstanding Graduate Student Award

\section{RESEARCH INTERESTS:}

Secondary Physical Education

Out-of-School Physical Activity Programs
Professional Development

Teacher Candidate Dispositions 


\section{TEACHING INTERESTS:}

Health-Related Physical Fitness

Physical Activity Promotion

Curriculum \& Instruction
Aquatics Related Courses

Theory \& Pedagogy

Pedagogical Content Knowledge

\section{PROFESSIOANL EXPERIENCE:}

Graduate Teaching Assistant, West Virginia University 2007-Present

Plan, instruct, and evaluate courses in the physical education teacher education and basic instruction programs. Supervise pre-service teachers in various field placements including student teaching. Conduct research related to professional development opportunities in the state and comprehensive school physical activity programs. Engage in service activities relevant to the department, college, state, and profession.

\section{Accomplishments:}

- Conducted a survey research project that investigated the effectiveness of the West Virginia Health and Physical Education Leadership Academy.

- Completed a survey research project that examined the professional development needs of the physical education teachers in the state of West Virginia.

- Received a $\$ 5000$ to develop and implement two sustainable physical activity programs at a local elementary school. The first program was a summer take-home family-based physical activity program for $3^{\text {rd }}, 4^{\text {th }}$, and $5^{\text {th }}$ grade students. The second program was a semi-structured recess program designed to promote activity for $2^{\text {nd }}-5^{\text {th }}$ grade students. Responsibilities included grant writing, budget management, program design, participant recruitment, research design, ordering equipment, and locating outside funding.

Graduate Teaching Assistant, West Virginia University

2006

Taught college-aged students study skills related to academic success and managed undergraduate teaching assistants. Students enrolled in the class were on academic probation and at-risk for suspension. Curriculum consisted of time management, study skills, goal setting, memory development and other topics related to student achievement and retention.

\section{Accomplishments:}

- Facilitated the development of study skills needed for at-risk students to succeed and assimilate into mainstream college coursework.

- Delivered the program to 47 college students who collectively achieved a passing rate of $95 \%$.

\section{CLINICAL TEACHING EXPERIENCE:}

Assistant Coach, Morgantown, WV

2009-Present Coach the Morgantown Maniacs Women's High School Rugby Football Club. Instruct participants in skill performance and tactical game play. Lead practice sessions and coach during games.

Guard Start Instructor, Morgantown, WV

Volunteered to teach a Red Cross sanctioned Guard Start course for a summer program offered by West Virginia University. Instruction in how to assist someone with symptoms of a head, neck, or back injury, how to perform a lifesaving assist, how to perform CPR, how to perform First Aid, and how to safely monitor a pool and perform junior lifeguarding duties. 
Swim Instructor/Head Lifeguard, West Virginia University, Morgantown, WV

2003-2009

Served as Swim Instructor for participants across a developmental perspective (ages 3-80). Taught children with Down Syndrome, ADD, Autism, Turrets Syndrome, Muscular Dystrophy, and Brittle Bone Syndrome. Oriented new lifeguards, organized, directed, and taught swim lessons, assisted with the Lifeguard Training Program, and helped certify new guards. Worked with the Fire Department and ROTC training programs

Student Teacher, Morgantown High School/Westwood Middle, WV 2007

Taught English in the public school system utilizing assignments based on creative writing, research paper writing, grammar, spelling, and reading and analyzing literature. Engaged students with various special needs including learning and behavior disorders.

- Cathy Hults (10th - 11th Grade English Co-Teaching Setting)

- Cindy Parsons (7th Grade English)

Pool Manager, Brooke Hills Park, Wellsburg, WV

Directed the swim lesson program at Brooke Hills Park community pool. Trained and prepared new instructors to teach swim lessons. Supervised the aquatics staff including the training of new instructors. Managed pool operations including chemicals and water quality.

Swim Lesson Instructor, Steubenville High School Pool, Steubenville, OH 2004

Taught swim lessons to participants between the ages of 3-8. Provided differentiated instruction for a child who demonstrated extreme fear of water.

Swim Lesson Director/Lifeguard, Follansbee Pool, Follansbee, WV 2000-2004 Directed and supervised the delivery of all swim lessons. Taught swim lessons to participants between the ages of 4 and 13. Instructed children with Down Syndrome, ADD, and seizure disorders. Guarded the pool and assisted with facility risk management.

\section{PROFESSIONAL AFFILIATION:}

American Alliance for Health, Physical Education, Recreation and Dance (AAHPERD)

Midwest District of the American Alliance for Health Physical Education, Recreation and Dance

National Association for Sport and Physical Education (NASPE)

National Association for Kinesiology \& Physical Education in Higher Education (NAKPEHE)

West Virginia Association for Health, Physical Education, Recreation and Dance (WVAHPERD)

\section{RELATED SKILLS:}

Communication Skills

- Excellent problem-solving and analytic skills

- Good written and oral communication skills

- Meticulous documentation skills

\section{Computer Skills}

- Established word processing, spreadsheet, database, presentation, and statistical software skills

\section{Professional Certification}

- 5-12 West Virginia State Teaching Licensure in English Education

- American Red Cross certified Lifeguarding Instructor 
- American Red Cross certified Water Safety Instructor Trainer

- American Red Cross certified Fundamentals of Instructor Training Trainer

- American Red Cross certified Lifeguard

- American Red Cross certified Water Safety Instructor

- American Red Cross certified CPR/AED for Lifeguards

- American Red Cross certified First Aid

\section{SCHOLARLY PAPERS:}

DiGiacinto, K.L. \& Jones, E.M.(in press). Create an Adventure Challenge: Using recess time to supplement physical activity during the school day. Strategies: A Journal for Physical and Sport Educators.

DiGiacinto, K.L., \& Housner, L.D. (2009). Professional development: The efficacy of the West Virginia Health and Physical Education Leadership Academy. Manuscript in preparation.

DiGiacinto. K.L., Bulger, S., \& Wiegand, R. (2009). Rethinking PETE program admissions to include teacher candidate dispositions. Manuscript in preparation.

DiGiacinto. K.L. (2009). The right to knowledge: A literature review of sexuality education in America. Manuscript in preparation.

\section{SCHOLARLY PRESENTATIONS:}

DiGiacinto, K., \& Housner, L. (2010, January). Molding Leaders: The Impact of the West Virginia Health and Physical Education Leadership Academy. Poster session presented at the NAKPEHE conference, Scottsdale, AZ.

DiGiacinto, K. (2009, October). The Mylan Park Summer Shape-up Challenge: A family-based approach to physical activity promotion. Paper presented at the WVAHPERD conference, Flatwoods, WV.

DiGiacinto, K., \& Housner, L. (2009, October). The Impact of the West Virginia Health and Physical Education Leadership Academy. Paper presented at the 2009 NASPE conference, Myrtle Beach, SC.

DiGiacinto, K., Bulger, S., \& Wiegand, R. (2009, January). Rethinking PETE program admissions to include teacher candidate dispositions. Paper presented at the NAKPEHE conference, Sarasota, FL.

Housner, L, DiGiacinto, K, \& Ramsey, C. (2008, November). Whistle while you work: Dopey strategies for formative assessment. Presented at the WVAHPERD conference, Davis, WV. 


\section{FUNDING HISTORY:}

$\$ 450.00 \quad$ Funding from the Coaching and Teaching Studies department to attend the 2010 AAHPERD convention. Indianapolis, IN. March 16-20, 2010. Additionally transportation was provided by the College of Physical Activity and Sport Sciences

\$700.00 Funding from the Coaching and Teaching Studies department to attend the 2010 NAKPEHE conference. Scottsdale, AZ. January 6-9, 2010

\$850.00 Funding from WVU College of Physical Activity and Sport Sciences and the Physical Education Teacher Education program to attend the NASPE Physical Education Conference in Myrtle Beach, SC. October 7-10, 2009

\$994.47 Funding from WVU College of Physical Activity and Sports Sciences to attend the National AAHPERD Convention in Tampa Bay, FL. March 31-April 4, 2009

\$200.00 Registration for the National AAHPERD Convention waived by Mike Davis, CEO of AAHPERD. March 31-April 4, 2009

$\$ 5,000.00 \quad$ America on the Move, West Virginia on the Move, Schools on the Move grant recipient March 15, 2009. Used to fund my dissertation research. Donations from local businesses, sports teams, and universities were also collected and estimated in excess of $\$ 54,200.00$

$\$ 450.00$ Graduate Student Travel Grant to present at the 2009 NAKPEHE conference. Sarasota, FL. January 4-6, 2009.

Room and board paid for by WVAAHPERD for the "Midwest AAHPERD Council for Future Professionals Leadership 2008" conference. Angola, IN. October 2-4, 2008.

\section{PROFESSIONAL SERVICE:}

Member of the planning committee for the first ever West Virginia Physical Activity Symposium, June 17-18, 2010. Duties included procuring sponsorship. In-kind contribution of $\$ 10,000.00$ from Subway of West Virginia to cover the travel and media costs of having Jared Fogle speak during the Symposium.

Harrison County Teachers Workshop - Presented how to conduct the Fitnessgram and HEAP assessments, December 14, 2009

Presented the Mylan Park Activity Challenge to the Preston County Wellness Committee. June 12, 2009

Helped instruct participants in the proper use of pedometers for the Active Living Every Day Online research project. September 6, 2008 
Reviewer for the Historic Traditions and Future Directions of Research on Teaching and Teacher Education in Physical Education publication. (Sections 4 and 5). Book citation is:

Housner, L.D., Metzler, M.W., Schempp, P.G, \& Templin, T.J. (Eds.). (2009) Historic Traditions and Future Directions of Research on Teaching and Teacher Education in Physical Education. Morgantown: Fitness Information Technology.

Brooke County Teachers Workshop - Presented on the topic of NASPE Standard 3: Physical Activity Assessment In and Outside of School, January 18, 2008

\section{TEACHING RESPONSIBILITIES:}

\begin{tabular}{|c|c|c|c|}
\hline Course & Title & Semester \& Year & Enrollment \\
\hline EDP 101 & Learn Stratgs-Academic Success & Spring 2006 & 18 \\
\hline EDP 101 & Learn Stratgs-Academic Success & Spring 2006 & 18 \\
\hline EDP 101 & Learn Stratgs-Academic Success & Fall 2006 & 7 \\
\hline EDP 101 & Learn Stratgs-Academic Success & Fall 2006 & 4 \\
\hline PET 358 & Teaching Softball/Baseball & Fall 2007 & 18 \\
\hline PET 452 & Teaching Outdoor Leisure Pursuits & Fall 2007 & 21 \\
\hline PE $157 *$ & Slow Pitch Softball & Fall 2007 & 26 \\
\hline PE $186 *$ & Outdoor Leisure Pursuits & Fall 2007 & 24 \\
\hline PET 358 & Teaching Softball/Baseball & Spring 2008 & 21 \\
\hline PET 452 & Teaching Outdoor Leisure Pursuits & Spring 2008 & 20 \\
\hline PE $157 *$ & Slow Pitch Softball & Spring 2008 & 23 \\
\hline PE $186 *$ & Outdoor Leisure Pursuits & Spring 2008 & 25 \\
\hline PET 233** & Pedagogy Theory/Application & Fall 2008 & 21 \\
\hline PET 358 & Teaching Softball/Baseball & Fall 2008 & 22 \\
\hline PE 157* & Slow Pitch Softball & Fall 2008 & 33 \\
\hline PET 233** & Pedagogy Theory/Application & Spring 2009 & 23 \\
\hline PET 358 & Teaching Softball/Baseball & Spring 2009 & 22 \\
\hline PE 157* & Slow Pitch Softball & Spring 2009 & 27 \\
\hline PE 173 & Beginning Swimming & Summer 2009 & 11 \\
\hline PE 175 & Lifeguard Training & Summer 2009 & 7 \\
\hline PET 324 & Water Safety Instructorship & Summer 2009 & 13 \\
\hline PET 358 & Teaching Softball/Baseball & Fall 2009 & 18 \\
\hline PET 228 & Curriculum & Fall 2009 & 20 \\
\hline PE 157* & Slow Pitch Softball & Fall 2009 & 25 \\
\hline PE 173 & Beginning Swimming & Fall 2009 & 15 \\
\hline PE 174 & Intermediate Swimming & Fall 2009 & 15 \\
\hline PET 349 & Fitness Education & Spring 2010 & 18 \\
\hline PET 358 & Teaching Softball/Baseball & Spring 2010 & 21 \\
\hline PE $101^{*}$ & Badminton & Spring 2010 & 48 \\
\hline
\end{tabular}




\section{STUDENT TEACHING SUPERVISION:}

Semester \& Year

Fall 2007

Spring 2008

Fall 2008

Spring 2009

Fall 2009

Spring 2010
Number of Student Teachers

2

2

6

6

2

4
Grade Level

Secondary

Secondary

Secondary

Secondary \& Elementary

Elementary

Secondary

\section{CONFERENCES ATTENDED:}

“Good to Great” 2010 NAKPEHE Conference. Scottsdale, AZ, January 6-9, 2010.

"Exploring and Ocean of Change" 2009 NASPE Conference on Physical Education Teacher Education. Myrtle Beach, SC. October 7-10, 2009.

“Many Voices One Mission” National AAHPERD Convention. Tampa Bay, FL. March 31-April 4, 2009

"History to Horizons, Understanding Our Past and Present, Constructing Our Future” 2009 NAKPEHE conference. Sarasota, FL. January 4-6, 2009

“Midwest AAHPERD Council for Future Professionals Leadership 2008” conference. Angola, IN. October 2-4, 2008.

"History and Future Directions of Research in Physical Education” conference. Pittsburgh, PA. October 11-14, 2007. 